Article

\title{
Differential Pricing and Emission Reduction in Remanufacturing Supply Chains with Dual-Sale Channels under CCT-Mechanism
}

\author{
Kaifu Yuan ${ }^{1, *}$, Guangqiang Wu ${ }^{1}$, Hui Dong ${ }^{1}$, Bo He $^{2}$ and Dafei Wang ${ }^{1}$ \\ 1 School of Business Administration, Guizhou University of Finance and Economics, Guiyang 550025, China; \\ guangqiangwu@163.com (G.W.); dhero.h@163.com (H.D.); wangdafei-jiayou@163.com (D.W.) \\ 2 School of Economics and Business Administration, Chongqing University, Chongqing 400000, China; \\ hebo@cqu.edu.cn \\ * Correspondence: kaifuy@mail.gufe.edu.cn
}

Received: 17 August 2020; Accepted: 28 September 2020; Published: 2 October 2020

\begin{abstract}
In order to make optimal decisions for pricing and emission reduction, a remanufacturing supply chain system with dual-sale channels is investigated. With regard to the preferences of consumers for different channels and carbon cap-and-trade mechanisms, profit-maximization models are developed on supply chain members and systems in decentralized and centralized cases. Based on a backward induction, the corresponding formulae for decision variables are obtained. Then the effect of the industry emission control coefficient is analyzed and the optimal decisions of two cases are compared. Finally, the coordination mechanism and numerical analysis are presented. The result indicates that: (1) As the free carbon allowances granted by the government to the manufacturer increases, the investment in carbon reduction from the manufacturer will increase. As the industry emission control coefficient increases, the carbon emissions per product and the prices of new and remanufactured products will decrease, while the demands of the new and remanufactured products and the profits of supply chain members and systems will increase. (2) As the direct sale channel preference coefficient increases, the profits of the manufacturer and the system will increase while the retailer's profit will decrease. Correspondingly, the carbon emissions of unit product will decrease, and the sales of the direct sale channel will increase while the sales of the retail channel will decrease. (3) The decision in the coordinated case not only ensures emission reduction and system profit to reach the level of the centralized case, but also raises the profits of supply chain members in the decentralized case. Therefore, it is preferable to other decisions. (4) As the carbon trading price increases, the emission reduction investment from the manufacturer will increase while the profits of the supply chain and its members will increase.
\end{abstract}

Keywords: remanufacturing supply chains; carbon cap-and-trade mechanism; dual-sale channels; differential pricing; carbon emissions

\section{Introduction}

To meet the increasingly individualized, diversified and enlarged demands of consumers, enterprises endeavor to expand their production capacity. Thus, a great amount of energy is consumed and a large number of waste products remain to be disposed of. For example, in 2017 alone, the total energy consumption and solid waste production in China's manufacturing industry were 2.43 billion and 3.316 billion tons, an increase of $55.8 \%$ and $102.2 \%$ over 2007 [1,2]. A rapid increase in energy consumption and waste products highlights the urgency of energy conservation and emission reduction, as well as waste product management and control. Effective measures have been taken in China to stipulate the recycling responsibility of producers for waste products and the trading 
rules of the carbon right market. For example, the Chinese government promulgated "Regulations on the Management of Waste Electrical and Electronic Products' Recycling" in 2009 and devised the mechanism of carbon cap-and-trade (CCT-mechanism for short) in 2017 [3]. The carbon trading mechanism means that to reduce carbon emissions, the government sets an industry control coefficient based on the historical emission intensity of enterprise to allocate free carbon emission allowances, and then the enterprise can buy or sell carbon emissions right in the carbon trading market according to its actual emissions. The industry emission control coefficient refers to the free carbon allowance ratio set by the government based on the historical emission value of the enterprise. The higher industry emission control coefficient the government grants, the more free carbon allowances the enterprise will receive, and the less pressure the carbon emission reduction will be faced with. Remanufacturing is an environmentally friendly production method of activities such as disassembling, inspecting, repairing/reworking and reassembling. It utilizes the main components of waste products to produce remanufactured products [4]. In other words, remanufactured products are the combinations of used, remanufactured and new components [5]. Nevertheless, remanufactured products are better than or approximate to the original new products (new products for short) in quality and performance. Compared with traditional manufacturing, remanufacturing consumes $40 \%$ of electricity and $30 \%$ of metal and emits $20 \%$ of air pollutants [6]. Remanufacturing is an important way to develop a circular economy, which can effectively reduce environmental pollution and improve economic benefits and social welfare [7]. Since remanufacturing has significant economic and environmental benefits, remanufacturing is gradually incorporated into manufacturers' production plans. Therefore, Xero, Kodak, Robert Bosch tools, Caterpillar, Delphi and other original equipment manufacturers (OEMs) have adopted remanufacturing [8,9]. So far, a remanufacturing supply chain (RSC for short) has taken shape. It consists of the forward supply chains and reverse supply chains. Manufacturers make new products in the former and recycle and remanufacture used products in the latter. To protect proprietary technologies, manufacturers tend to remanufacture themselves. However, due to the different acceptability of customers, the selling prices of new products are greater than those of remanufactured products. Moreover, with the advent of e-commerce, in addition to selling products through retailers, manufacturers can also sell products through online channels themselves, such as Sony, Apple, IBM, Dell, HP and others [10]. Take Dell and HP for example. Dell sells remanufactured products via the online channel "Dell Outlet" and new products via retail and online stores [11]. HP also sells remanufactured computers in online outlet stores [12]. Under a CCT-mechanism, enterprises are faced with the increasing pressure to reduce emission and investment in carbon emissions reduction will be unavoidable. In addition, with the rise of online direct selling channels, it is also very important for enterprises to coordinate traditional sale channels and online direct sale channels. Obviously, when introducing the CCT-mechanism and dual-sale channels, to obtain a greater profits of supply chain system and members, besides considering the competition between different sale channels, it is essential to coordinate different participants' decisions and manufacturers' production, pricing and emission reduction investment decisions, which makes remanufacturing supply chains' decisions very complicated. Therefore, under a CCT-mechanism, the purpose of this article is to determine the optimal pricing and emission reduction decisions of different participants, and design appropriate contracts to raise the profits of supply chain members and systems.

Here, differential pricing and emission reduction decisions on a remanufacturing supply chain with dual-sale channels are investigated under a CCT-mechanism considering the customers' channel preference. Furthermore, our study is conducted in such a situation: there are new products and remanufactured products (both types of products for short) to sell simultaneously in direct sale and retail channels (both channels for short) at different prices, and both types of products have completely independent markets. In addition, carbon emission reduction investment and an industry emission control coefficient are introduced. To the best of our knowledge, this has not been done before. Three decision-making structures, decentralized, centralized and coordinated cases, will be analyzed. This paper will address the following questions: 
(1) Do fewer free carbon emission allowances raise the carbon emission reduction investment of enterprises?

(2) With regard to cap-and-trade mechanisms and dual-sale channels, how do manufacturers and retailers make pricing and emission reduction decisions?

(3) What will happen to the enterprises' pricing and emission reduction decisions when the industry emission control coefficient changes?

(4) How will variation in influencing factors such as direct sales channel preferences and carbon trading prices affect the decisions of enterprises' pricing and emission reduction decisions?

(5) What is the best way to raise the profits of the system and members and reduce the carbon emission of the unit product?

Here is the outline of the rest of the paper. The closely related literature review is conducted in Section 2. Related assumptions, notations and profit functions are given in Section 3. The optimal pricing and emission decisions on different decision-making structures are formulated and compared in Section 4. A revenue-sharing contract is designed in Section 5. Related results are validated and more managerial insights are obtained by a numerical analysis in Section 6. Finally, our work is summarized and some suggestions for further research are enclosed in Section 7, and related proofs are given in the appendices for clarity.

\section{Literature Review}

This paper involves major aspects of research in RSC: (1) production and pricing decisions in accordance with carbon emission regulations; (2) dual-sale channel pricing and selection.

\subsection{Production and Pricing Decisions in Accordance with Carbon Emission Regulations}

When carbon emission regulations are given, their effects on the production and pricing of enterprises will draw a growing number of researchers' attention. Based on the CCT-mechanism, to determine optimal outputs per period, Chang et al. (2015) develop profit-maximization models of two periods, respectively, when demands are independent and alternative. They argue that manufacturing and remanufacturing decisions are greatly affected by the CCT-mechanism, and that compared with carbon caps, carbon prices can control production and emissions more effectively [13]. Under a charging legislation on emission, Yenipazarli (2016) attempts to determine whether or when remanufacturing decisions will reduce the overall effect of enterprises on the environment and how to levy emission taxes to obtain the benefits of remanufacturing in society, economy and environment, and he develops two-period models with remanufacturing or not [14]. To compare grandfathering with benchmarking, Chang et al. (2017) develop two models under a CCT-mechanism. They find that when manufacturers are motivated to adopt low-carbon technology, benchmarking is more effective than grandfathering [15]. García-Alvarado et al. (2017) analyzes the effect of environmental legislation on inventory control policies under a CCT-mechanism. Based on cost and environmental performance, they compare system operation under traditional and green inventory policies. The results show that a higher carbon price can motivate enterprises to pay more attention to technology investment decisions [16]. Wang et al. (2017) put forward four single-period models, i.e., two models not considering carbon emissions without/with capital constraint and two models considering carbon emissions without/with capital constraint. They investigate how the initial capital, carbon cap and carbon price affect manufacturing/remanufacturing decisions. In such cases, new products are more costly than remanufactured ones. Furthermore, when remanufactured products are not available, they will be replaced by new ones to meet customers' needs [17]. Chai et al. (2018) manage to determine the favorable conditions for monopoly manufacturers to make more profits under a CCT-mechanism. They propose four models for the ordinary market and the green market, and further divide each market into two scenarios, i.e., remanufacturing without/with CCT-mechanism. The results indicate that the CCT-mechanism is important for remanufacturing in these two markets [18]. Chen et al. (2018) 
assume that new products' prices are different from remanufactured products' and that they are sold in different markets. They explore the effect of the CCT-mechanism along with the take-back regulation on carbon emissions, and analyze a single manufacturer's decisions on production and collection. They find that the implementation of a CCT-mechanism will be helpful for the environment [19]. Turki et al. (2018) endeavor to obtain optimal storage and manufacturing/remanufacturing planning. They develop two models considering carbon emissions or not. Their results show that the reduction in the carbon cap and maintaining high carbon trading prices encourage manufacturers to remanufacture used products and reduce carbon emissions [20]. Kundu and Chakrabarti (2018) do some research to find how production, collection, remanufacturing and inventory management operational decisions are affected by carbon tax, a strict carbon cap and carbon cap-and-trade. They develop two types of models without/with carbon emission regulations and suggest that remanufacturing reduces carbon emissions more efficiently than manufacturing [21]. Wang et al. (2018) focus on how the carbon emission tax affects decisions of manufacturing and remanufacturing. They develop a decision model with a two-period horizon and conclude that a higher carbon tax requires the manufacturer to invest in low-carbon technologies [22]. Shu et al. (2018) compare the trade-old-for-remanufactured (TOR) models with consumer willingness to pay and product durability considered in two cases, i.e., without/with carbon tax constraint. They explore how the carbon emissions of enterprises are affected by carbon tax and government subsidies. Their study shows that when the government formulates right carbon tax and subsidy policies, carbon emissions will decrease while enterprises' profits will increase [23]. Similarly, Miao et al. (2018) consider the TOR or the trade-old-for-new policy and develop models without/with carbon regulations. Carbon regulations consists of the carbon tax policy and the CCT-mechanism. Their results demonstrate that the adoption of carbon regulations will help raise remanufactured products' sales but reduce new ones' sales [24]. Dou et al. (2019) consider the difference of the tax prices in manufacturing and remanufacturing periods. They develop two-period models with and without remanufacturing. Their results indicate that to protect the environment and improve the manufacturer's profit, the tax price needs to be raised or lowered during manufacturing or remanufacturing periods [25].

Although the above-mentioned researchers make optimal production and pricing decisions of different carbon emission regulations, their research only deals with the monopolist manufacturer who makes production and pricing decisions but ignore the effect of other participants' actions. In addition, they rarely consider carbon emission investment and assume that consumers have no channel preference. Furthermore, all the above-mentioned researchers adopting CCT-mechanism, except Chang et al. (2017) [15], suppose that free carbon emission allowances is a constant and has nothing to do with the current production quantity and the industry emission control coefficient.

\subsection{Dual-Sale Channel Pricing and Channel Selection}

Very few studies have dealt with the dual-sale channel pricing and channel selection. To make pricing decisions, Gao et al. (2016) investigate three game models, in which both types of products are sold by manufacturers through both channels while used ones are collected by retailers. However, they suppose that both types of products are of the same quality and products of both channels are sold in the same price. Furthermore, neither manufacturer's sale cost nor coordination between members of supply chains is considered [26]. Wang et al. (2016) try to choose right sale channels for both types of products. Considering customers' different value judgments and selling prices of both types of products, they develop three channel structures: (1) independent retailers sell new products and remanufactured ones, (2) traditional retailers sell the former while manufacturers sell the latter by direct channels, and (3) manufacturers sell the former by direct channels while retailers sell the latter. They assume zero production cost per remanufactured product and disregard the recycling cost for used products. Their results show that dual-channel strategies have always been the best choice for manufacturers and consumers but harmful to retailers [27]. Gan et al. (2017) deal with how separating sale channels affects the profit of supply chains, the customer's pay preference and 
pricing differentiation. They propose a pricing strategy for new products and remanufactured ones in a closed-loop supply chain (CLSC for short) with separate channels, i.e., retailers sell the former while manufacturers sell the latter ones by direct channels. Their work suggests that compared with single channels (Gan et al. 2015) [28], the total supply chains' profit can be raised by separating channels [29]. Yang et al. (2018) manage to obtain optimal decisions on pricing and emission reduction for the manufacturer under a CCT-mechanism. They establish the models considering remanufacturing or not, where both types of products' prices remain the same in both channels. Their result shows that the level of carbon emission reduction can be improved by remanufacturing and that an appropriate emission reduction cost factor is very important to improve firm profits and reduce carbon emissions [30]. Based on Gan et al. (2017) [29], to make the optimal channel and pricing decisions of the manufacturer and the optimal subsidy level of the government, He et al. (2019) investigate three possible channel structures: (1) selling new products and remanufactured ones by retailers and third-party platforms, respectively; (2) selling the former by direct channels while selling the latter by third-party platforms; (3) selling the latter by direct channels while selling the former by retailers [31].

Up to now, except Yang et al. (2018) [30], no other researchers have considered CCT-mechanism and carbon emission reduction investment. In comparison, the work of Yang et al. (2018) [30] is closest to ours. They not only consider the CCT-mechanism and carbon emission reduction investment but also adopt the historic intensity method to allocate free carbon emission allowances. However, they assume that new products are identical to remanufactured ones in both channels. They also assume that free carbon emission allowances is a constant, which has nothing to do with the industry emission control efficient and the actual output. In addition, we also find a problem in some articles on dual-channel pricing and channel selection disregard of remanufacturing. For example, from Table 2 of $\mathrm{Xu}$ et al. (2018) [32], we notice that under a decentralized scenario and improved revenue-sharing contract, the direct prices are lower than the wholesale prices, which means the retail channel will disappear. At this point, dual-sale channels become a single-sale channel, which also motivates us to solve this problem.

The CCT-mechanism is an effective method to reduce carbon emissions because it encourages enterprises to bargain carbon emission credits on the carbon right market. From 2003 to now, 12 states (provinces) and seven cities covering 35 countries, such as the EU, Australia, Canada, Japan, China and the USA, have established carbon trading systems (Chen et al. 2018) [19]. Therefore, under a CCT-mechanism a remanufacturing supply chain with both channels will be investigated to derive the optimal pricing and emission reduction decisions. To sum up, the following major contributions are made in this paper: (1) On the allocation of the free carbon emission allowances, we adopt the historic intensity method. It closely relates the free carbon emission allowances with the current production quantity and the industry emission control coefficient. (2) We assumed that consumers differently evaluate new products and remanufactured ones, that the manufacturer is required to make an investment to reduce carbon emissions, and that the sale cost is lower in the direct sale channel than in the retail sale channel. (3) The solution procedures are developed for the models in decentralized and centralized cases (two cases for short). (4) A contract of revenue-sharing is designed to raise the profits of the manufacturer and the retailer in the decentralized case. To solve these problems, based on Stackelberg games, three scenarios are investigated and the related factors on supply chain performance are analyzed: the industry emission control coefficient, the channel preference coefficient and the carbon trading price. Our work offers some new managerial insights that enable the government to set free carbon emission allowances more scientifically on one hand and the enterprises to obtain the optimal decisions on pricing and carbon emission reduction on the other hand.

\section{Problem Description and Assumption}

A dual-sale channel RSC system with the manufacturer and retailer is given in Figure 1. The demand of customers is satisfied by both types of products from the retail channel and the direct sale channel online (the direct sale channel for short). From the Stackelberg games, we develop 
manufacturer-led models, and their decision sequences are as follows: (1) the manufacturer's pricing and emission reduction decisions are proposed. It consists of the wholesale prices $w_{n}\left(w_{r}\right)$ and direct sale prices $p_{m n}\left(p_{m r}\right)$ for new products (remanufactured products) and carbon emission reduction per product $\Delta e$. (2) Based on the manufacturer's decisions, the retailer determines his retail prices $p_{r n}\left(p_{r r}\right)$ for new products (remanufactured products). Of course, to obtain sufficient used products for remanufacturing, the retailer recycles used products at the buyback price $p_{j}$ and then resells to the manufacturer at the transfer price $(1+\sigma) p_{j}$, where $\sigma$ represents the return on the investment of the retailer for recycling used products. Since the manufacturer produces carbon emissions in manufacture and remanufacture, similar to Chen et al. (2018) [19], carbon emissions per new product and remanufactured product are assumed to be $e_{n}$ and $e_{r}$, respectively, and $e_{n}>e_{r}$. Moreover, under a CCT-mechanism, based on the historical intensity method, the free carbon emission allowances are allocated. It is affected by the actual output and the industry emission control coefficient $a$, where $a$ indicates the emission reduction pressures of different industries the government sets. The greater the $a$ grows, the more the manufacturer receives free carbon emission allowances. When the free carbon emission allowances are less or greater than the actual carbon emissions, insufficient or excess carbon credits will be bargained at the carbon trading price $p_{c}$ by the manufacturer through the carbon right market.

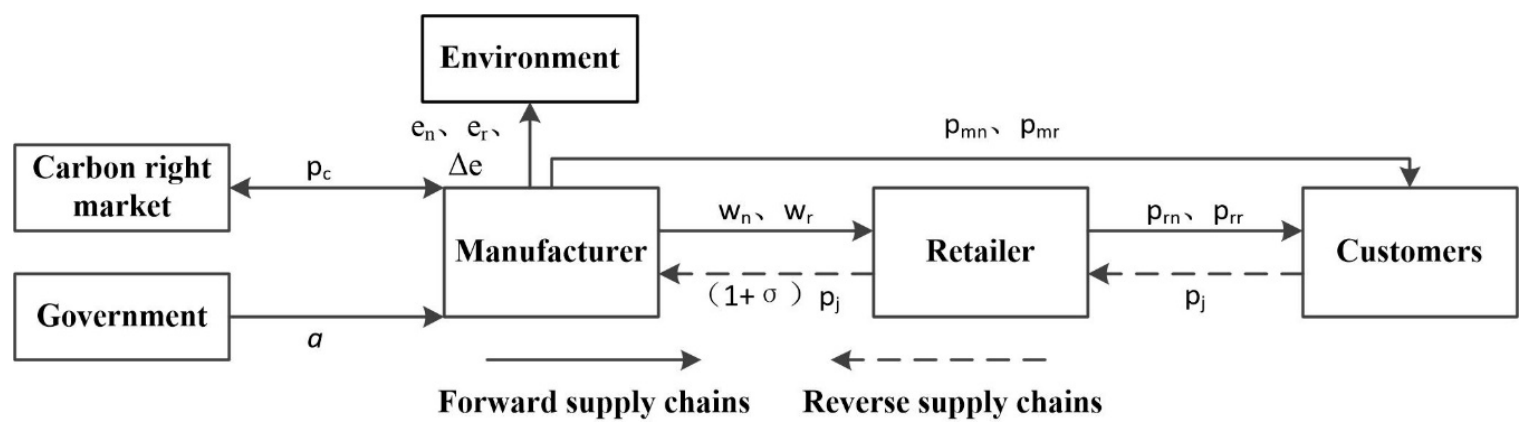

Figure 1. A dual-sale channel RSC system under CCT-mechanism.

Combining with industry practice and simplifying the complex conditions, the notation, definition and unit of variables are as shown in Table 1.

Table 1. The notation, definition and unit of variables in the paper.

\begin{tabular}{|c|c|c|}
\hline Notation & Definition & Unit \\
\hline$w_{i}$ & $\begin{array}{l}\text { the wholesale price per i product, } \mathrm{i} \in\{n, r\}, \mathrm{n} \text { and } \mathrm{r} \text { represent new and } \\
\text { remanufactured, respectively, the same below }\end{array}$ & yuan/unit \\
\hline$p_{m i}$ & the direct sale price per i product, $\mathrm{i} \in\{n, r\}$ & yuan/unit \\
\hline$p_{r i}$ & the retail price per i product, $\mathrm{i} \in\{n, r\}$ & yuan/unit \\
\hline$\Delta e$ & carbon emission reduction per product & $\mathrm{kg} / \mathrm{unit}$ \\
\hline$\lambda$ & the investment scale coefficient of carbon emission reduction & yuan $\cdot$ unit $^{2} / \mathrm{kg}^{2}$ \\
\hline$e_{i}$ & carbon emissions per i product, $\mathrm{i} \in\{n, r\}$ & $\mathrm{kg} / \mathrm{unit}$ \\
\hline$c_{i}$ & production cost per i product, $\mathrm{i} \in\{n, r\}$ & yuan/unit \\
\hline$c_{d}\left(c_{h}\right)$ & $\begin{array}{l}\text { the cost of the manufacturer (retailer) selling unit product through the } \\
\text { direct sale (retail) channel }\end{array}$ & yuan/unit \\
\hline$\sigma$ & the return on the investment per used product & - \\
\hline$p_{j}$ & the buyback price per used product & yuan/unit \\
\hline$a$ & the industry emission control coefficient & - \\
\hline$x$ & customers' preference coefficient for the direct sale channel & - \\
\hline
\end{tabular}


Table 1. Cont.

\begin{tabular}{clc}
\hline Notation & \multicolumn{1}{c}{ Definition } & Unit \\
\hline$p_{c}$ & the trading price per carbon credit & yuan/kg \\
\hline$Q_{i}$ & the initial capacity of i product market, $\mathrm{i} \in\{n, r\}$ & unit \\
\hline$D_{m i}$ & the demand of i products in the direct sale channel, $\mathrm{i} \in\{n, r\}$ & unit \\
\hline$D_{r i}$ & the demand of i products in the retail channel, $\mathrm{i} \in\{n, r\}$ & unit \\
\hline$D_{i}$ & total demand of i products, $\mathrm{i} \in\{n, r\}, D_{n}=D_{r n}+D_{m n}$ and $D_{r}=D_{r r}+D_{m r}$ & unit \\
\hline$\pi_{m}\left(\pi_{r}\right)$ & the manufacturer (the retailer) profit & yuan \\
\hline$\pi_{T}$ & the total profit & yuan \\
\hline$D C(C C)$ & decentralized case (centralized case) & - \\
\hline$N P(R P)$ & new products (remanufactured products) & - \\
\hline$N P R(R P R)$ & new products (remanufactured products) in the retail channel & - \\
\hline$N P D(R P D)$ & new products (remanufactured products) in the direct sale channel & - \\
\hline$M(R, S C)$ & manufacturer (retailer, supply chain) & \\
\hline
\end{tabular}

Here, $w_{n}, w_{r}, p_{m n}, p_{m r}, \Delta e, p_{r n}$ and $p_{r r}$ are decision variables. All the unit of variables below are the same as shown in Table 1, so they are omitted. The assumptions are given as follows.

Assumption 1. When the free carbon emission allowances are allocated by the historical strength method, the free carbon emission allowances $=$ the actual output $\times$ the historical intensity value $\times$ the industry emission control coefficient. The actual output represents the number of products actually produced in a year. The historical intensity value is the weighted average of carbon emission intensity during the enterprise's benchmark years (generally nearly three years) (HPDRC, 2018; SDRC, 2017) [33,34]. We assume that the manufacturing and remanufacturing technology for the manufacturer has remained unchanged for the past three years. In other words, before the manufacturer invests in carbon emission reduction, carbon emissions per new product (remanufactured product) are a constant, which are equal to their historical intensity values.

Assumption 2. The investment in carbon emission reduction by the manufacturer (equipment renewal, production process improvement, etc.) is usually a one-time investment for a period of time. The effect of carbon emission reduction is enhanced as the manufacturer raises their carbon emission reduction investment. The manufacturer's investment in carbon emission reduction is assumed to be $\lambda \Delta e^{2} . \lambda$ represents the investment scale coefficient of carbon emission reduction and $\lambda>0 ; \Delta e$ indicates carbon emission reduction per product (Liu et al. 2018) [35].

Assumption 3. Due to insufficient awareness and low acceptance of remanufactured products, consumers believe that new products are superior to remanufactured ones. In addition, consumers can easily distinguish remanufactured products from new products owing to the distinctive remanufactured product logo. For these reasons, the prices of remanufactured products are usually $60 \%$ of those of the new product. Both types of products often serve different consumer groups, which also makes remanufactured products relatively less effective than new ones. Therefore, we assume that the new products and the remanufactured ones have their independent markets, respectively, and that the initial market capacities for new products and remanufactured ones are $Q_{n}$ and $Q_{r}$, respectively, $Q_{n}>Q_{r}$.

Assumption 4. Similar to the hypothesis of Xu et al. (2018) [32], both types of products are sold simultaneously in both channels, and the same type of products compete in different sale channels. In general, compared with the direct sale channel, consumers can enjoy a better after-sales service when purchasing products in the retail channel. Therefore, the consumers' preference coefficients for the retail channel and direct sale channel are assumed to be 1 and $x$, respectively, $0<x<1$. A larger $x$ brings about a higher consumers' acceptance level to products purchased from the direct sale channel. The expected values to new products and remanufactured products of consumers are dictated by an even distribution of $\left[0, Q_{i}\right], i \in\{n, r\}$. 
Assumption 5. The selling costs per product of the retailer in the retail channel and the manufacturer in the direct sale channel are $c_{h}$ and $c_{d}$, respectively, where $c_{h}>c_{d}$. To simplify models, the fixed selling costs of manufacturers via the direct sale channel, the fixed selling costs of retailers via the retail channel, and the wholesaling costs of retailers are not considered. To ensure that both channels of two types of products coexist, we assume that $c_{h}-c_{d} \leq(1-x) Q_{i} \leq c_{h}+c_{d}, i \in\{n, r\}$.

From Appendix A, we get the demand functions of new products in both channels as follows:

$$
\begin{gathered}
D_{r n}=\left\{\begin{array}{c}
Q_{n}-\frac{p_{r n}-p_{m n}}{1-x}, p_{m n} \leq x p_{r n} \\
Q_{n}-p_{r n}, p_{m n}>x p_{r n}
\end{array}\right. \\
D_{m n}=\left\{\begin{array}{c}
\frac{x p_{r n}-p_{m n}}{x(1-x)}, p_{m n} \leq x p_{r n} \\
0, p_{m n}>x p_{r n}
\end{array}\right.
\end{gathered}
$$

Similarly, the demand functions of remanufactured products in both channels are as follows:

$$
\begin{gathered}
D_{r r}=\left\{\begin{array}{c}
Q_{r}-\frac{p_{r r}-p_{m r}}{1-x}, p_{m r} \leq x p_{r r} \\
Q_{r}-p_{r r}, p_{m r}>x p_{r r}
\end{array}\right. \\
D_{m r}=\left\{\begin{array}{c}
\frac{x p_{r r}-p_{m r}}{x(1-x)}, p_{m r} \leq x p_{r r} \\
0, p_{m r}>x p_{r r}
\end{array}\right.
\end{gathered}
$$

From Equations (1)-(4), in both channels we will have four cases on the demand functions of both types of products-i.e., when the direct sales price of both types of products is less than a certain percentage of the retail price, both types of products exist in both channels and we get Case 1; when the direct sales price of the new product is less than a certain percentage of the retail price and the direct sales price of the remanufactured product is greater than a certain percentage of the retail price, new products exist in both channels and remanufactured products only exist in the retail channel, and we get Case 2; when the direct sales price of new products is greater than a certain percentage of the retail price and the direct sales price of remanufactured products is less than a certain percentage of the retail price, new products only exist in retail channels and remanufactured products exist in both channels, and we get Case 3; when the direct sales prices of both types of products are greater than a certain percentage of the retail price, both types of products only exist in the retail channels and we get Case 4.

Case 1: When $p_{m n} \leq x p_{r n}$ and $p_{m r} \leq x p_{r r}$,

$$
D_{r n}=Q_{n}-\frac{p_{r n}-p_{m n}}{1-x}, D_{m n}=\frac{x p_{r n}-p_{m n}}{x(1-x)}, D_{r r}=Q_{r}-\frac{p_{r r}-p_{m r}}{1-x}, D_{m r}=\frac{x p_{r r}-p_{m r}}{x(1-x)} .
$$

In Case 1, both types of products are sold via both channels.

Case 2: When $p_{m n} \leq x p_{r n}$ and $p_{m r} \leq x p_{r r}$,

$$
D_{r n}=Q_{n}-\frac{p_{r n}-p_{m n}}{1-x}, D_{m n}=\frac{x p_{r n}-p_{m n}}{x(1-x)}, D_{r r}=Q_{r}-p_{r r}, D_{m r}=0
$$

In Case 2, new products are sold via both channels while remanufactured ones are sold only via the retail channel.

Case 3: When $p_{m n} \leq x p_{r n}$ and $p_{m r} \leq x p_{r r}$,

$$
D_{r n}=Q_{n}-p_{r n}, D_{m n}=0, D_{r r}=Q_{r}-\frac{p_{r r}-p_{m r}}{1-x}, D_{m r}=\frac{x p_{r r}-p_{m r}}{x(1-x)} .
$$

In Case 3, new products are sold only via the retail channel while remanufactured ones are sold via both channels. 
Case 4: When $p_{m n}>x p_{r n}$ and $p_{m r}>x p_{r r}$,

$$
D_{r n}=Q_{n}-p_{r n}, D_{m n}=0, D_{r r}=Q_{r}-p_{r r}, D_{m r}=0 .
$$

In Case 4, both types of products are sold only via the retail channel. At this time, the direct sale channel disappears.

Since Case 1 is the most complicated of the above four cases, the paper will only study this case. Clearly, if we can make the optimal pricing and emission reduction decisions of Case 1, then the corresponding decisions for the other three cases will be naturally available. Therefore, from Appendix A, for Case 1, the demand functions of new products in both channels are as follows:

$$
\begin{gathered}
D_{r n}=Q_{n}-\frac{p_{r n}-p_{m n}}{1-x} \\
D_{m n}=\frac{x p_{r n}-p_{m n}}{x(1-x)}
\end{gathered}
$$

The demands of remanufactured products in both sale channels are as follows:

$$
\begin{gathered}
D_{r r}=Q_{r}-\frac{p_{r r}-p_{m r}}{1-x} \\
D_{m r}=\frac{x p_{r r}-p_{m r}}{x(1-x)}
\end{gathered}
$$

In consequence, the profit functions of supply chain members and its system are as follows:

$$
\begin{gathered}
\pi_{m}=\quad w_{n} D_{r n}+p_{m n} D_{m n}-c_{n}\left(D_{r n}+D_{m n}\right)+w_{r} D_{r r}+p_{m r} D_{m r} \\
\quad-\left[c_{r}+(1+\sigma) p_{j}\right]\left(D_{r r}+D_{m r}\right)+\left(a e_{n}-e_{n}+\Delta e\right) p_{c}\left(D_{r n}+D_{m n}\right) \\
\quad+\left(a e_{r}-e_{r}+\Delta e\right) p_{c}\left(D_{r r}+D_{m r}\right)-c_{d}\left(D_{m n}+D_{m r}\right)-\lambda \Delta e^{2} \\
\pi_{r}=\left(p_{r n}-w_{n}\right) D_{r n}+\left(p_{r r}-w_{r}\right) D_{r r}+\sigma p_{j}\left(D_{m r}+D_{r r}\right)-c_{h}\left(D_{r n}+D_{r r}\right) \\
\pi_{T}=\pi_{m}+\pi_{r}=p_{r n} D_{r n}+p_{m n} D_{m n}-c_{n}\left(D_{r n}+D_{m n}\right)+p_{r r} D_{r r}+p_{m r} D_{m r} \\
-\left(c_{r}+p_{j}\right)\left(D_{r r}+D_{m r}\right)+\left(a e_{n}-e_{n}+\Delta e\right) p_{c}\left(D_{r n}+D_{m n}\right) \\
+\left(a e_{r}-e_{r}+\Delta e\right) p_{c}\left(D_{r r}+D_{m r}\right)-c_{d}\left(D_{m n}+D_{m r}\right)-c_{h}\left(D_{r n}+D_{r r}\right)-\lambda \Delta e^{2}
\end{gathered}
$$

In Equation (9), $w_{n} D_{r n}+p_{m n} D_{m n}$ is the revenue of the manufacturer selling new products, $c_{n}\left(D_{r n}+D_{m n}\right)$ is the cost of the manufacturer producing new products, $w_{r} D_{r r}+p_{m r} D_{m r}$ is the revenue of both types of products, $\left[c_{r}+(1+\sigma) p_{j}\right]\left(D_{r r}+D_{m r}\right)$ is the cost of the manufacturer buying back used products from the retailer and producing remanufactured products, $\left(a e_{n}-e_{n}+\Delta e\right) p_{c}\left(D_{r n}+D_{m n}\right)+$ $\left(a e_{r}-e_{r}+\Delta e\right) p_{c}\left(D_{r r}+D_{m r}\right)$ is the cost or benefit of the manufacturer through carbon trading, and $c_{d}\left(D_{m n}+D_{m r}\right)$ is the manufacturer's selling cost through the direct sale channel. In Equation (10), $\left(p_{r n}-w_{n}\right) D_{r n}+\left(p_{r r}-w_{r}\right) D_{r r}$ is the profit of the retailer selling both types of products, $\sigma p_{j}\left(D_{m r}+D_{r r}\right)$ is the profit of the retailer reselling used products, and $c_{h}\left(D_{r n}+D_{r r}\right)$ is the retailer's selling cost through the retail channel.

\section{Model Development and Solution}

In general, the manufacturer and the retailer are independent entities in the supply chain. They often make decisions independently for their own profit maximization, i.e., the decentralized case. In addition, to further raise profits, the manufacturer often cooperates with the retailer to maximize the system profit and make decisions as a whole, i.e., the centralized case. Therefore, in this section, these two types of decision-making models will be developed, solved, compared and discussed. 


\subsection{Decentralized Case}

In this case, not only the manufacturer but also the retailer focus decision-making on their own profit maximization, and the corresponding decision-making model is as follows:

$$
\begin{array}{ll}
\max _{w_{n}, w_{r}, \Delta e, p_{m n}, p_{m r}} \pi_{m} & =w_{n} D_{r n}+p_{m n} D_{m n}-c_{n}\left(D_{r n}+D_{m n}\right)+w_{r} D_{r r}+p_{m r} D_{m r} \\
& -\left[c_{r}+(1+\sigma) p_{j}\right]\left(D_{r r}+D_{m r}\right)+\left(a e_{n}-e_{n}+\Delta e\right) p_{c}\left(D_{r n}+D_{m n}\right) \\
& +\left(a e_{r}-e_{r}+\Delta e\right) p_{c}\left(D_{r r}+D_{m r}\right)-c_{d}\left(D_{m n}+D_{m r}\right)-\lambda \Delta e^{2} \\
\text { s.t. } p_{m n} \geq w_{n,} \quad p_{m r} \geq w_{r} \\
\max _{p_{r n}, p_{r r}} \pi_{r}=\left(p_{r n}-w_{n}\right) D_{r n}+\left(p_{r r}-w_{r}\right) D_{r r}+\sigma p_{j}\left(D_{m r}+D_{r r}\right)-c_{h}\left(D_{r n}+D_{r r}\right)
\end{array}
$$

Theorem 1. In the decentralized case, when $p_{c}^{2}(1-x)-2 \lambda(x-2)^{2}<0, \pi_{m}$ is a joint concave function with respect to (w.r.t for short) $w_{n}, w_{r}, \Delta e, p_{m n}, p_{m r}$, which has a unique maximum value. Here, we get the manufacturer's optimal pricing and emission reduction decisions $\left(w_{n}^{D C}, w_{r}^{D C}, p_{m n}^{D C}, p_{m r}^{D C}, \Delta e^{D C}\right)(D C$ indicates decentralized case), the retailer's optimal pricing decisions $\left(p_{r n}^{D C}, p_{r r}^{D C}\right)$ and the corresponding product demands $\left(D_{m n}^{D C}, D_{m r}^{D C}, D_{r n}^{D C}, D_{r r}^{D C}\right)$, where

$$
\begin{gathered}
w_{n}^{D C}=\frac{4 \lambda x\left(Q_{n}+A-c_{h}\right)-p_{c}^{2}\left[x\left(Q_{n}+Q_{r}\right)+A-F+2 Q_{n}-2 c_{d}-2 c_{h}\right]}{4\left(2 \lambda x-p_{c}^{2}\right)} \\
w_{r}^{D C}=\frac{4 \lambda x\left(Q_{r}+F-c_{h}\right)-p_{c}^{2}\left[x\left(Q_{n}+Q_{r}\right)-A+F+2 Q_{r}-2 c_{d}-2 c_{h}\right]}{4\left(2 \lambda x-p_{c}^{2}\right)} \\
p_{m n}^{D C}=\frac{4 \lambda x\left(x Q_{n}+A+c_{d}\right)-p_{c}^{2}\left[x\left(3 Q_{n}+Q_{r}\right)+A-F\right]}{4\left(2 \lambda x-p_{c}^{2}\right)} \\
p_{m r}^{D C}=\frac{4 \lambda x\left(x Q_{r}+F+c_{d}\right)-p_{c}^{2}\left[x\left(Q_{n}+3 Q_{r}\right)-A+F\right]}{4\left(2 \lambda x-p_{c}^{2}\right)} \\
p_{r n}^{D C}=\frac{2 \lambda x\left(3 Q_{n}-x Q_{n}+2 A+c_{d}+c_{h}\right)-p_{c}^{2}\left(x Q_{r}+A-F+3 Q_{n}+c_{h}-c_{d}\right)}{4\left(2 \lambda x-p_{c}^{2}\right)} \\
p_{r r}^{D C}=\frac{2 \lambda x\left(3 Q_{r}-x Q_{r}+2 F+c_{d}+c_{h}\right)-p_{c}^{2}\left(x Q_{n}-A+F+3 Q_{r}+c_{h}-c_{d}\right)}{4\left(2 \lambda x-p_{c}^{2}\right)} \\
D_{m n}^{D C}=\frac{p_{c}\left[x\left(Q_{n}+Q_{r}\right)-A-F-2 c_{d}\right]}{2\left(2 \lambda x-p_{c}^{2}\right)} \\
D_{m r}^{D C}=\frac{4 \lambda x\left(x Q_{r}-F-c_{d}\right)-p_{c}^{2}\left(x Q_{r}-x Q_{n}+A-F\right)}{4 x\left(2 \lambda x-p_{c}^{2}\right)}-\frac{(1-x) Q_{r}-c_{h}+c_{d}}{4(1-x)} \\
D_{r n}^{D C}=\frac{(1-x) Q_{n}-c_{h}+c_{d}}{4(1-x)} \\
D_{r r}^{D C}=\frac{(1-x) Q_{r}-c_{h}+c_{d}}{4(1-x)}
\end{gathered}
$$

For proof of Theorem 1, please see Appendix B, where $A=c_{n}-p_{c} e_{n}(a-1), F=c_{r}+(1+\sigma) p_{j}-$ $p_{c} e_{r}(a-1)$. Substituting Equations (14)-(24) into Equations (9) and (10), we get the maximum profits of the corresponding members in the decentralized case.

Corollary 1. $\frac{\partial \Delta e^{D C}}{\partial a}>0, \frac{\partial w_{n}^{D C}}{\partial a}<0, \frac{\partial w_{r}^{D C}}{\partial a}<0, \frac{\partial p_{m n}^{D C}}{\partial a}<0, \frac{\partial p_{m r}^{D C}}{\partial a}<0, \frac{\partial p_{r}^{D C}}{\partial a}<0, \frac{\partial p_{r r}^{D C}}{\partial a}<0, \frac{\partial D_{n}^{D C}}{\partial a}>0, \frac{\partial D_{r}^{D C}}{\partial a}>0$. 
Proofs of Corollary 1 are given in Appendix C. In the decentralized case, as the industry emission control coefficient increases, i.e., as the free carbon emission allowances granted from the government increase, the manufacturer will raise their investment in carbon emission reduction technologies. In consequence, carbon emissions per product are reduced and the production process becomes more eco-friendly. In addition, with the increase in the industry control coefficient, the selling prices of both types of products decrease and their demand increases. It is helpful to recycle and remanufacture used products and develop a circular economy.

\subsection{Centralized Case}

In this case, the supply chain will be taken as a whole, with the system profit maximization as its decision goal. Its decision-making model is as follows:

$$
\begin{aligned}
\max _{p_{m n}, p_{m r}, \Delta e, p_{r n}, p_{r r}} \pi_{T} & =p_{r n} D_{r n}+p_{m n} D_{m n}-c_{n}\left(D_{r n}+D_{m n}\right)+p_{r r} D_{r r}+p_{m r} D_{m r} \\
& -\left(c_{r}+p_{j}\right)\left(D_{r r}+D_{m r}\right)+\left(a e_{n}-e_{n}+\Delta e\right) p_{c}\left(D_{r n}+D_{m n}\right) \\
& +\left(a e_{r}-e_{r}+\Delta e\right) p_{c}\left(D_{r r}+D_{m r}\right)-c_{d}\left(D_{m n}+D_{m r}\right)-c_{h}\left(D_{r n}+D_{r r}\right)-\lambda \Delta e^{2}
\end{aligned}
$$

Theorem 2. In the centralized case, when $p_{c}^{2}(1-x)-4 \lambda<0, \pi_{T}$ is a joint concave function w.r.t $w_{n}, w_{r}, \Delta e, p_{m n}, p_{m r}$, which has a unique maximum value within the range of values. Here, we get the supply chain system's optimal pricing and emission reduction decisions $\left(p_{m n}^{C C}, p_{m r}^{C C}, p_{r n}^{C C}, p_{r r}^{C C}, \Delta e^{C C}\right)(C C$ indicates the centralized case) and the product demands $\left(D_{m n}^{C C}, D_{m r}^{C C}, D_{r n}^{C C}, D_{r r}^{C C}\right)$, where

$$
\begin{gathered}
p_{m n}^{C C}=\frac{4 \lambda x\left(x Q_{n}+A+c_{d}\right)-p_{c}^{2}\left[\left(3 Q_{n}+Q_{r}\right) x+A-E\right]}{4\left(2 \lambda x-p_{c}^{2}\right)} \\
p_{m r}^{C C}=\frac{4 \lambda x\left(x Q_{r}+E+c_{d}\right)-p_{c}^{2}\left[\left(Q_{n}+3 Q_{r}\right) x-A+E\right]}{4\left(2 \lambda x-p_{c}^{2}\right)} \\
p_{r n}^{C C}=\frac{4 \lambda x\left(Q_{n}+A+c_{h}\right)-p_{c}^{2}\left[\left(Q_{n}+Q_{r}\right) x+A-E+2 Q_{n}+2 c_{h}-2 c_{d}\right]}{4\left(2 \lambda x-p_{c}^{2}\right)} \\
p_{r r}^{C C}=\frac{4 \lambda x\left(Q_{r}+E+c_{h}\right)-p_{c}^{2}\left[\left(Q_{n}+Q_{r}\right) x-A+E+2 Q_{r}+2 c_{h}-2 c_{d}\right]}{4\left(2 \lambda x-p_{c}^{2}\right)} \\
D_{m n}^{C C}=\frac{4 \lambda x\left(x Q_{n}-A-c_{d}\right)-p_{c}^{2}\left[\left(Q_{n}-Q_{r}\right) x-A+E\right]}{4 x\left(2 \lambda x-p_{c}^{2}\right)}-\frac{(1-x) Q_{n}-c_{h}+c_{d}}{2(1-x)} \\
D_{m r}^{C C}=\frac{4 \lambda x\left(x Q_{r}-E-c_{d}\right)-p_{c}^{2}\left[\left(Q_{r}-Q_{n}\right) x+A-E\right]}{4 x\left(2 \lambda x-p_{c}^{2}\right)}-\frac{(1-x) Q_{n}-c_{h}+c_{d}}{2(1-x)} \\
D_{r n}^{C C}=\frac{(1-x) Q_{n}-c_{h}+c_{d}}{2(1-x)} \\
D_{r r}^{C C}=\frac{(1-x) Q_{r}-c_{h}+c_{d}}{2(1-x)}
\end{gathered}
$$

For proofs of Theorem 2, please see Appendix D, where $A=c_{n}-p_{c} e_{n}(a-1), E=c_{r}+p_{j}-p_{c} e_{r}(a-1)$. Substituting Equations (26)-(34) into Equation (11), we get the maximum system profit in the centralized case.

Corollary 2. $\frac{\partial \Delta e^{C C}}{\partial a}>0, \frac{\partial p_{m n}^{C C}}{\partial a}<0, \frac{\partial p_{m r}^{C C}}{\partial a}<0, \frac{\partial p_{r n}^{C C}}{\partial a}<0, \frac{\partial p_{r r}^{C C}}{\partial a}<0, \frac{\partial D_{n}^{C C}}{\partial a}>0, \frac{\partial D_{r}^{C C}}{\partial a}>0$. 
Proofs of Corollary 2 are given in Appendix E. Moreover, the conclusion from Corollary 2 is consistent with that from Corollary 1 . Therefore, relevant managerial insights will not be repeated here.

\subsection{Comparison of Two Cases}

Corollary 3. $\Delta e^{D C}<\Delta e^{C C}, p_{m n}^{D C}>p_{m n}^{C C}, p_{m r}^{D C}>p_{m r}^{C C}, p_{r n}^{D C}>p_{r n}^{C C}, p_{r r}^{D C}>p_{r r}^{C C}, D_{n}^{D C}<D_{n}^{C C}, D_{r}^{D C}<D_{r}^{C C}$, $\pi_{m}^{D C}+\pi_{r}^{D C}<\pi_{T}^{C C}$.

Corollary 3 has been proved in Appendix F. It shows that since larger optimal carbon emission reduction per product is required in the centralized case than in the decentralized case, the manufacturer is required to raise the carbon emission reduction investment in the centralized case. Thus, carbon emissions per product are reduced and the production process becomes more environment-friendly. In addition, although the selling prices in the centralized case are lower, the increased sales revenue is far greater than the increased carbon emission investment costs and other related costs, and hence the system makes a higher profit. Obviously, the centralized case is more advantageous in the improvement of the system profit and the reduction in carbon emissions per product. In the centralized case, the existence of the CCT-mechanism is beneficial to consumers, supply chain, and the natural environment. Consumers can buy products at a lower price. The profit of the supply chain system increases, and the greenhouse gas emissions per unit product to nature are reduced. Particularly, the manufacturer raises investment in carbon emission reduction in the centralized case. In this sense, strengthening the cooperation between enterprises is of special significance to reduce product carbon emissions.

\section{Design of Supply Chain Coordination Mechanism}

Corollary 3 shows that compared with the centralized case, the decentralized case is not conducive to product market expansion and the reduction in unit product carbon emissions. The system profit is lower in the decentralized case than the centralized case. These problems are solved by making product prices and carbon emission reductions reach the optimal values in the centralized case. Both types of products are sold at lower prices $\left(w_{n}^{S}, w_{r}^{S}\right)$ to the retailer and the retailer's sale revenue of the ratio $\psi \in(0,1)$ is transferred to the manufacturer. Here $S$ indicates the supply chain coordination mechanism. Therefore, a contract of revenue-sharing $\left(w_{n}^{S}, w_{r}^{S}, \psi\right)$ is obtained. Then, we get the corresponding profits for supply chain members as follows:

$$
\begin{aligned}
& \pi_{m}^{S}=\left(\psi p_{r n}+w_{n}^{S}\right) D_{r n}+p_{m n} D_{m n}-c_{n}\left(D_{r n}+D_{m n}\right)+\left(\psi p_{r r}+w_{r}^{S}\right) D_{r r} \\
&+p_{m r} D_{m r}-\left[c_{r}+(1+\sigma) p_{j}\right]\left(D_{r r}+D_{m r}\right)+\left(a e_{n}-e_{n}+\Delta e\right) p_{c}\left(D_{r n}+D_{m n}\right) \\
&+\left(a e_{r}-e_{r}+\Delta e\right) p_{c}\left(D_{r r}+D_{m r}\right)-c_{d}\left(D_{m n}+D_{m r}\right)-\lambda \Delta e^{2} \\
& \pi_{r}^{S}=\left[(1-\psi) p_{r n}-w_{n}^{S}\right] D_{r n}+\left[(1-\psi) p_{r r}-w_{r}^{S}\right] D_{r r}+\sigma p_{j}\left(D_{r r}+D_{m r}\right)-c_{h}\left(D_{r n}+D_{r r}\right)
\end{aligned}
$$

From Equations (35) and (36), with the backward induction, we get the following relationships between decision variables:

$$
\begin{gathered}
p_{r n}^{S}=\frac{(1-x)(1-\psi) Q_{n}+(1-\psi) p_{m n}^{S}+w_{n}^{S}+c_{h}}{2(1-\psi)} \\
p_{r r}^{S}=\frac{(1-x)(1-\psi) Q_{r}+(1-\psi) p_{m r}^{S}+w_{r}^{S}+c_{h}}{2(1-\psi)} \\
\Delta e^{S}=\frac{p_{c}\left[\left(Q_{n}+Q_{r}\right) x-p_{m n}^{S}-p_{m r}^{S}\right]}{2 \lambda x}
\end{gathered}
$$

Theorem 3. When the contract parameters $\left(w_{n}^{S}, w_{r}^{S}, \psi\right)$ satisfy 


$$
\begin{aligned}
w_{n}^{S} & =\frac{\left\{-4 \lambda x\left(x Q_{n}+A-c_{d}+2 c_{h}\right)+p_{c}^{2}\left[\left(3 Q_{n}+Q_{r}\right) x+A-E-4 c_{d}+4 c_{h}\right]\right\} \psi}{4\left(2 \lambda x-p_{c}^{2}\right)} \\
& +\frac{4 \lambda x\left(x Q_{n}+A-c_{d}\right)-p_{c}^{2}\left[\left(3 Q_{n}+Q_{r}\right) x+A-E-4 c_{d}\right]}{4\left(2 \lambda x-p_{c}^{2}\right)} \\
w_{r}^{S} & =\frac{\left\{-4 \lambda x\left(x Q_{r}+E-c_{d}+2 c_{h}\right)+p_{c}^{2}\left[\left(Q_{n}+3 Q_{r}\right) x-A+E-4 c_{d}+4 c_{h}\right]\right\} \psi}{4\left(2 \lambda x-p_{c}^{2}\right)} \\
& +\frac{4 \lambda x\left(x Q_{r}+E-c_{d}\right)-p_{c}^{2}\left[\left(Q_{n}+3 Q_{r}\right) x-A+E-4 c_{d}\right]}{4\left(2 \lambda x-p_{c}^{2}\right)}
\end{aligned}
$$

and

$$
\begin{aligned}
& \frac{\sigma p_{j}\left(D_{m r}^{C C}+D_{r r}^{C C}\right)-c_{h}\left(D_{r n}^{C C}+D_{r r}^{C C}\right)+\left(p_{r n}^{C C}-w_{n}^{S}\right) D_{r n}^{C C}+\left(p_{r r}^{C C}-w_{r}^{S}\right) D_{r r}^{C C}-\pi_{r}^{D C}}{D_{r n}^{C C} p_{r n}^{C C}+D_{r r}^{C C} p_{r r}^{C C}} \geq \psi \\
& \geq \frac{A\left(D_{m n}^{C C}+D_{r n}^{C C}\right)+F\left(D_{m r}^{C C}+D_{r r}^{C C}\right)-\Delta e p_{c}\left(D_{m n}^{C C}+D_{m r}^{C C}+D_{r n}^{C C}+D_{r r}^{C C}\right)+c_{d}\left(D_{m n}^{C C}+D_{m r}^{C C}\right)}{D_{r n}^{C C} p_{r n}^{C C}+D_{r r}^{C C} p_{r r}^{C C}} \\
& +\frac{-D_{m n}^{C C} p_{m n}^{C C}-D_{m r}^{C C} p_{m r}^{C C}-D_{r n}^{C C} w_{n}^{S}-D_{r r}^{C C} w_{r}^{S}+\lambda\left(\Delta e^{C C}\right)^{2}+\pi_{m}^{D C}}{D_{r n}^{C C} p_{r n}^{C C}+D_{r r}^{C C} p_{r r}^{C C}}
\end{aligned}
$$

where, compared with decentralized case, under a coordination mechanism the manufacturer and the retailer can make more profits, and $A=c_{n}-p_{c} e_{n}(a-1), E=c_{r}+\sigma p_{j}-p_{c} e_{r}(a-1), F=c_{r}+(1+\sigma) p_{j}-p_{c} e_{r}(a-1)$. See Appendix G for the proof of Theorem 3.

\section{Numerical Example}

To verify the above-mentioned conclusions, a numerical example is given. It is assumed that $c_{n}=30, c_{r}=15, p_{j}=5, \sigma=0.5, e_{n}=500, e_{r}=350, Q_{n}=500, Q_{r}=250, \lambda=0.1, c_{d}=25, c_{h}=30$, $x=0.9$. Combined with the actual situation of China's carbon right market, we suppose $p_{c}=0.15$, $a=0.9$.

\subsection{Comparison of Different Cases}

Substituting related parameters into Theorem 1 and Theorem 2, the corresponding optimal results in two cases are obtained (Table 2) in agreement with the conclusion of Corollary 3. In addition, while substituting its relevant parameters into Theorem 3 to verify its validity, a contract of revenue sharing is found that enables the manufacturer and the retailer to make more profits in the decentralized case for $\psi \in(0.50,0.75)$. Here, we suppose $\psi=0.7$ and get the revenue-sharing contract $\left(w_{n}^{S}, w_{r}^{S}, \psi\right)=$ $(42.35,6.76,0.70)$ and the corresponding decision results shown in Table 2. According to Table 2, we get conclusions as follows.

(1) Compared with the decentralized case, the total demands for both types of products in the centralized case increase. In the centralized case, retail prices for new products and remanufactured ones decrease by $4.12 \%$ and $4.56 \%$, respectively, and their direct sale prices decrease by $0.04 \%$ and $1.12 \%$, respectively, and hence their demands increase in the retail channel by $100 \%$ and decrease in the direct sale channel by $89.93 \%$ and $71.45 \%$, respectively. Compared with the direct sale prices, there is a bigger decrease in the retail prices. It makes the retail channel more attractive to consumers than the direct sale channel, hence some consumers change from using the latter to the former. Since the increase in the demands of the retail channel is more than the decrease in the demands of the direct sale channel, the total demands for both types of products in the centralized case increase slightly by $0.04 \%$ and $1.26 \%$, respectively, and hence the total demand for the supply chain increases by $0.44 \%$.

(2) Compared with the decentralized case, carbon emission reduction and the system profit in centralized case increases. In the centralized case, the carbon emission reduction per product increases by $0.45 \%$ and therefore the manufacturer's carbon reduction investment cost increases by $0.89 \%$. However, in the centralized case, since the total sale revenue increases by $3.11 \%$ and the total sale revenue increases more than the total cost, there is an increase of $2.49 \%$ in the system profit. Here, the total cost consists of the carbon emission reduction cost, production cost and sales cost. 
(3) The design of the supply chain coordination mechanism can ensure not only that the system profit in the coordinated case reaches the level of the centralized case, but also that the manufacturer and the retailer make more profits in the decentralized case. Indeed, the system profit in the decentralized case is less than that in the centralized case. However, the centralized case is an ideal state since it is hard to achieve centralized decision-making in reality and to reasonably allocate the system profit. Introduction of the revenue-sharing contract can succeed in making the system profits of the coordinated and centralized cases equal and allow the supply chain members to be flexible in making decisions independently and raising their profits. For example, compared with the decentralized case, the adoption of a revenue-sharing contract $(42.35,6.76$, 0.70 ) enables the manufacturer and retailer to raise profits by $2.05 \%$ and $16.95 \%$, respectively.

In summary, by the comparison of three cases in Table 2, the decision-making effect of the coordinated case is found to be the best.

Table 2. Comparison of results of numerical examples in different decision cases.

\begin{tabular}{cccc}
\hline Variables & Decentralized Case & Centralized Case & Coordinated Case \\
\hline$w_{n}$ & 233.76 & & 42.35 \\
$w_{r}$ & 103.88 & & 6.76 \\
$p_{m n}$ & 236.26 & 236.17 & 236.17 \\
$p_{m r}$ & 118.88 & 117.54 & 117.54 \\
$p_{r n}$ & 275.01 & 263.67 & 263.67 \\
$p_{r r}$ & 138.88 & 132.54 & 132.54 \\
$\Delta e$ & 266.55 & 267.74 & 267.74 \\
$D_{m n}$ & 125.00 & 12.59 & 12.59 \\
$D_{m r}$ & 67.91 & 19.39 & 19.39 \\
$D_{r n}$ & 112.50 & 225.00 & 225.00 \\
$D_{r r}$ & 50.00 & 100.00 & 100.00 \\
$D_{n}$ & 237.49 & 237.59 & 237.59 \\
$D_{r}$ & 117.91 & 119.39 & 119.39 \\
$\pi_{m}$ & $59,199.67$ & & $60,410.31$ \\
$\pi_{r}$ & 1810.39 & & 2117.24 \\
$\pi_{T}$ & $61,010.06$ & $62,527.55$ & $62,527.55$ \\
\hline
\end{tabular}

\subsection{Effect of the Industry Emission Control Coefficient on Decision Results}

To better understand the effect of the industry emission control coefficient $a$ on the decision results, supposing $a \in[0.8,1]$ and substituting the relevant parameters into Theorem 1 and Theorem 2, we get the effect of the variation of $a$ on prices, carbon emission reduction, demands and profits in two cases shown in Figure 2, from which the following results are obtained:

(1) As the industry emission control coefficient increases, the demands for both types of products increase while their selling prices decrease. From Figure 2a,b, when $a$ increases from 0.8 to 1 in two cases, the direct sale prices for new products decrease from 240.46 and 240.38 to 232.05 and 231.96 , respectively, and both are down $3.50 \%$. The direct sale prices for remanufactured products decrease from 121.96 and 120.63 to 115.80 and 114.46, respectively; i.e., decrease $5.05 \%$ and $5.11 \%$, respectively. The retail prices for new products (remanufactured products) decrease by $3.01 \%(3.14 \%)$ and $4.34 \%(4.55 \%)$, respectively. From Figure $2 \mathrm{c}, \mathrm{d}$, it is likely that, when $a$ increases from 0.8 to 1 in the decentralized and centralized cases, the demands of new products (remanufactured products) in the direct sale channel increase by $7.76 \%(117.93 \%)$ and $10.62 \%$ $(42.89 \%)$, respectively. In dual channels, the total demands of new products both increase by $4.01 \%$ while those of remanufactured products increase by $5.98 \%$ and $5.91 \%$, respectively. Obviously, with the increase in $a$, the more manufacturer's free carbon emission allowances are granted by the government, and the less emission reduction pressure the manufacturer faces. To obtain higher profits, both types of products charge lower prices.

(2) As the industry emission control coefficient increases, the manufacturer's carbon emission reduction investment increases and both types of products become more environment-friendly. 
From Figure 2e, when $a$ increases from 0.8 to 1 in two cases, the carbon emission reductions per product increase by $4.66 \%$ and $4.64 \%$, respectively, which requires the manufacturer to invest in the reduction in carbon emissions per product.

(3) Raising the industry emission control coefficient helps improve the profits of the system and members. From Figure 2f, when $a$ increases from 0.8 to 1, the profits of the manufacturer and the retailer increase by $8.45 \%$ and $0.95 \%$, respectively, while the system profit increases by $8.01 \%$.
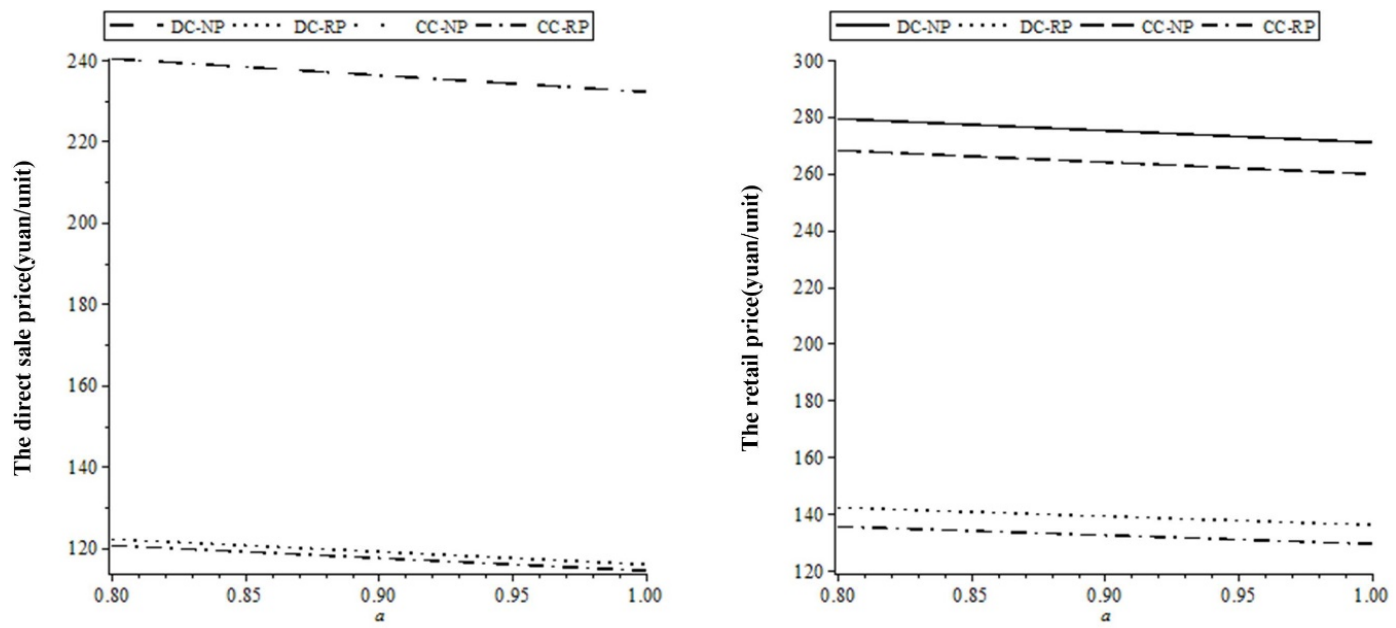

(a) The direct sale price changes with $a$

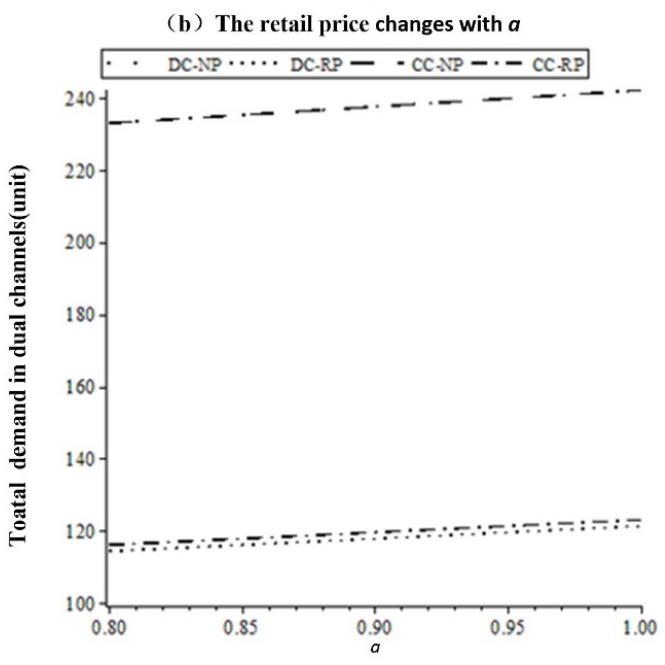

(d) Total demand in dual channels changes with $a$

(c) Demand in the direct sale Channel changes with $a$

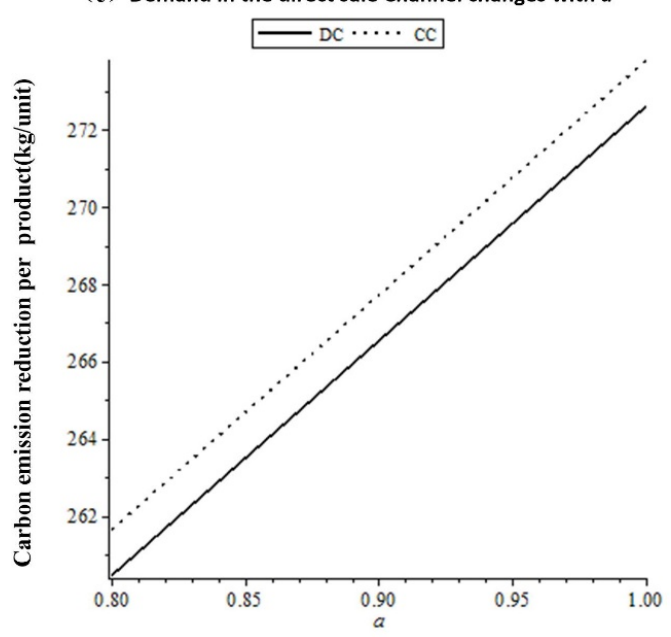

(e) Carbon emission reduction per product changes with $a$

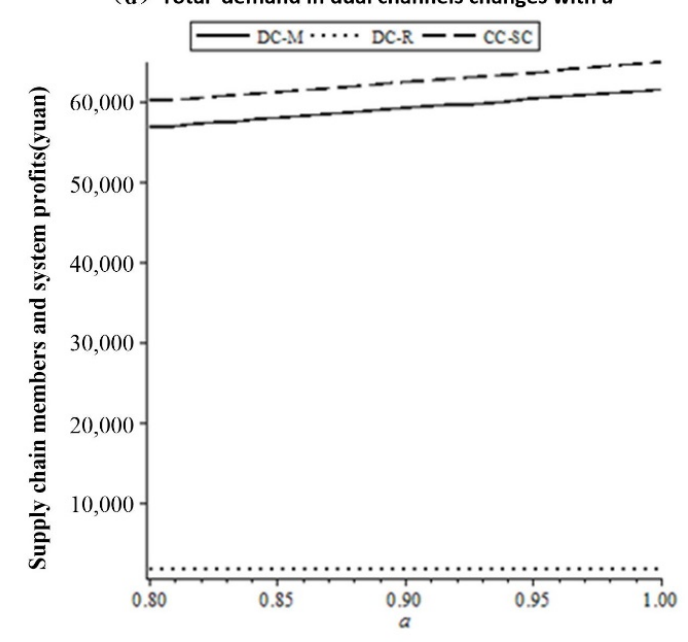

(f) Supply chain members and system profits change with $a$

Figure 2. The impact of $a$ on decision results in the decentralized and centralized cases. 
In short, the above results are consistent with Corollary 1 and Corollary 2.

\subsection{Effect of the Channel Preference Coefficient on Decision Results}

Here, supposing the direct sale channel preference coefficient $x \in[0.9,0.95]$ and substituting the relevant parameters into Theorem 1 and Theorem 2, we get the effect of the variation of $x$ on sale prices, carbon emission reduction, demands, and profits in two cases, as shown in Figure 3. Here are the results:
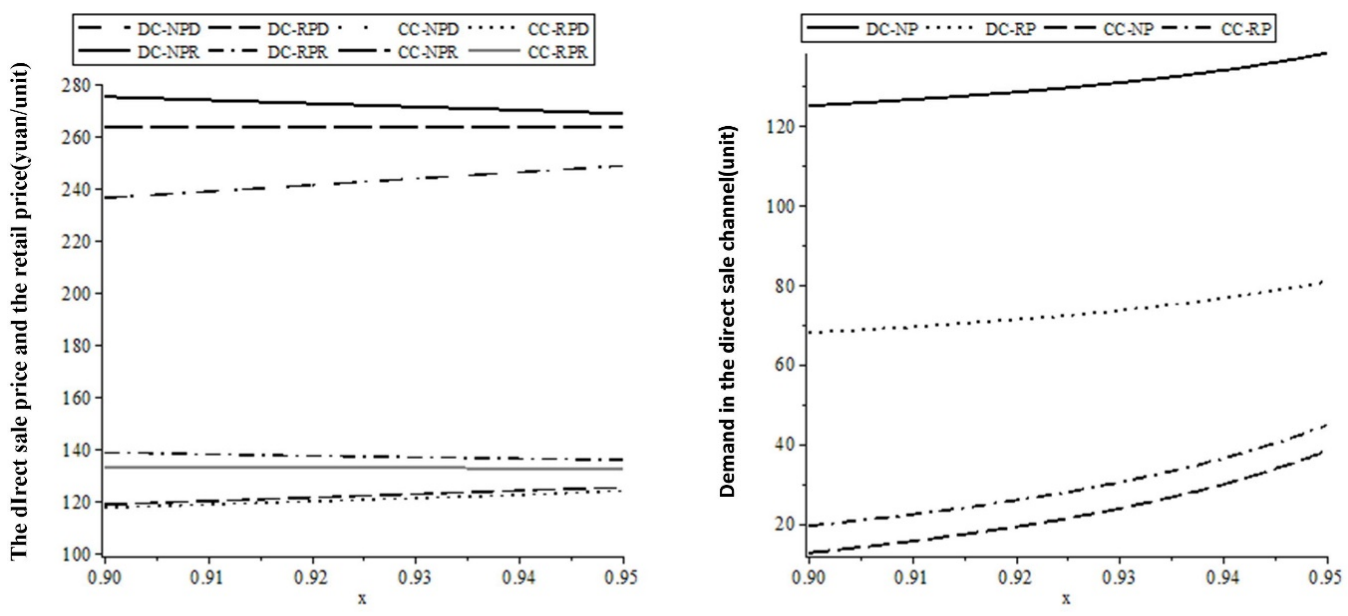

(a) The direct sale price and the retail price change with $x$

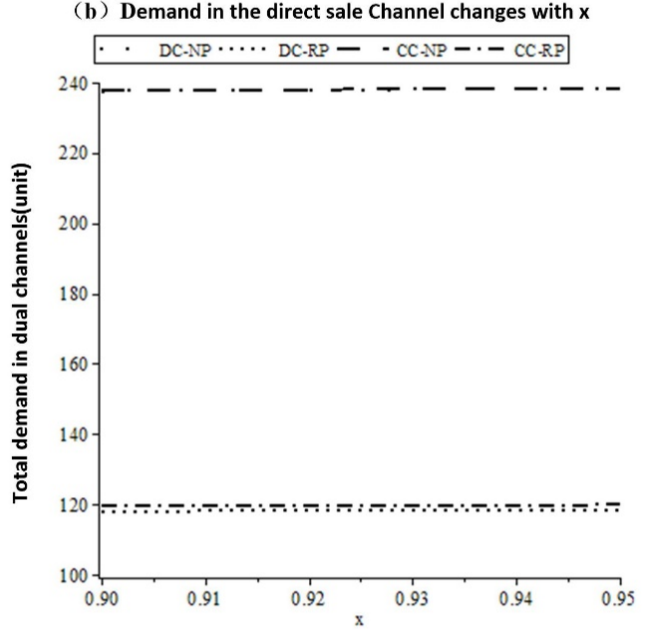

(c) Demand in the retail channel changes with $\mathrm{x}$

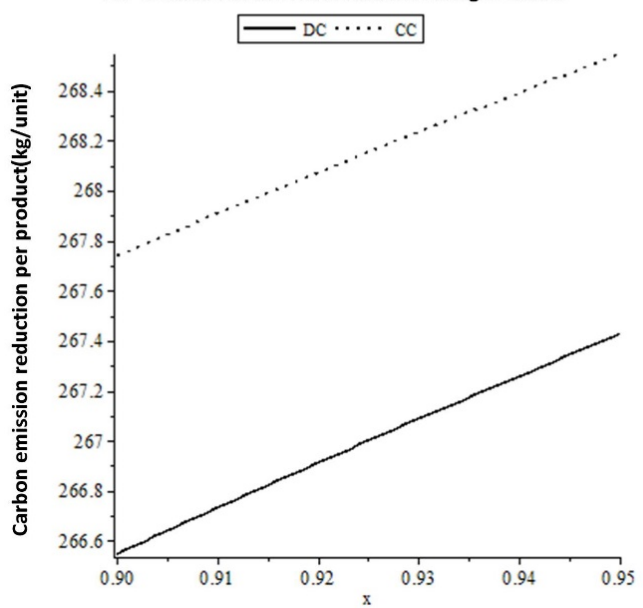

Total demand in dual channels changes with $x$

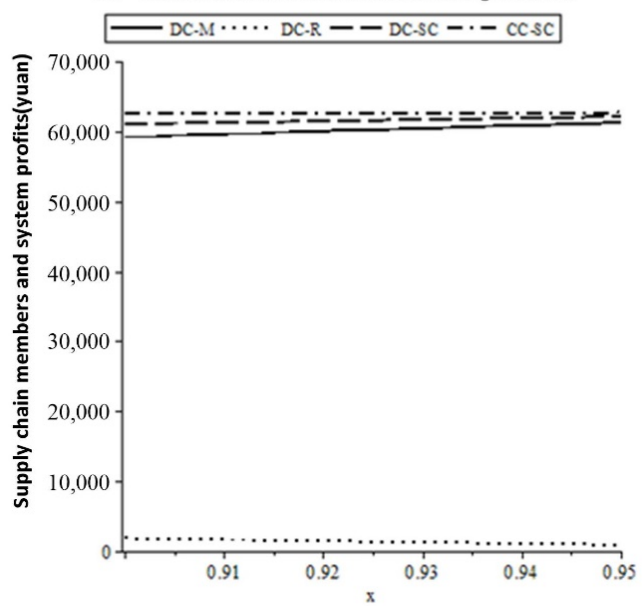

(f) Supply chain members and system profits change with $\mathrm{x}$

(e) Carbon emission reduction per product changes with $x$

Figure 3. The impact of $x$ on decision results in the decentralized and centralized cases. 
(1) With the increase in the direct sale channel preference coefficient, the profits of the manufacturer and the system increase but the retailer profit decreases. From Figure $3 \mathrm{a}-\mathrm{c}$, when $x$ increases from 0.9 to 0.95 in two cases, the direct sale prices for new products increase from 236.26 and 236.17 to 248.69 and 248.61 , respectively, i.e., increase by $5.26 \%$ and $5.27 \%$ while the direct sale prices for remanufactured products increase from 118.88 and 117.54 to 125.07 and 123.73, respectively, i.e., increase by $5.21 \%$ and $5.27 \%$. In contrast, the retail prices for new products (remanufactured products) in two cases decrease by $2.30 \%(0.02 \%)$ and $2.30 \%(0.05 \%)$, respectively. Correspondingly, in two cases, the demands for new products (remanufactured products) in the direct channel increase by $10.58 \%(204.29 \%)$ and $19.05 \%$ (130.79\%), respectively, while those in the retail channel decreased by $11.11 \%(11.11 \%)$ and $25.00 \%(25.00 \%)$, respectively. Since the increase in the demand of the direct sale channel is larger than the reduction in the demand of the retail channel, the total demands in dual channels increase by a little bit. From Figure 3d, in two cases, the total demands for new products increase from 237.49 and 237.59 to 238.22 and 238.31 , respectively, i.e., increase by $0.31 \%$ and $0.30 \%$ while those of remanufactured products increase from 117.91 and 119.39 to 118.35 and 119.75 , respectively, i.e., increase by $0.37 \%$ and $0.30 \%$. As a result, from Figure $3 \mathrm{f}$, in the decentralized case the manufacturer profit increases from $59,199.67$ to $61,205.57$, i.e., increases by $3.39 \%$ while the retailer profit decreases from 1810.39 to 866.19 , i.e., decreases by $52.15 \%$. Even so, the system profit in the decentralized case increases from $6,010.06$ to $62,071.75$, i.e., increases by $1.74 \%$ while that in the centralized case increases from $62,527.55$ to $62,643.82$, i.e., increases by $0.19 \%$. Clearly, when the consumers' preference coefficient to the direct sale channel increases, the consumers who purchase products through this channel will increase and hence the direct sale prices will increase. In response to the competition from the direct sale channel, the retail prices have to decrease. In consequence, the retailer profit coupled with demand will decrease. Since the manufacturer's initial profit is much larger than the retailer's, the system profits in two cases will increase.

(2) The increase in the direct sale channel preference coefficient requires the manufacturer to raise the carbon emission reduction investment and hence products are more environment-friendly. From Figure 3e, when $x$ increases from 0.9 to 0.95 in the two cases, the carbon emission reductions per product increase by $0.33 \%$ and $0.30 \%$, respectively. Consequently, the manufacturer will increase carbon emissions reduction investment and further reduce carbon emissions per product.

\subsection{Effect of the Carbon Trading Price on Decision Results}

To study how the carbon trading price $p_{c}$ affects decision results, supposing $p_{c} \in[0.1,0.17]$ and substituting the above parameters into Theorem 1 and Theorem 2, we get the effect of the variation of $p_{c}$ on sale prices, carbon emission reduction, demands, and profits in two cases as shown in Figure 4. Here are the results:

(1) The increase in the carbon trading price helps reduce the direct sale prices and the retail prices and raise demands and the profits for the system and members. From Figure $4 \mathrm{a}, \mathrm{b}$, in two cases, when $p_{c}$ increases from 0.1 to 0.17 , the direct sale prices of the new product decrease from 246.71 and 246.67 to 230.07 and 229.95 , respectively, i.e., decrease by $6.74 \%$ and $6.78 \%$. The direct sale prices of remanufactured products decrease from 129.71 and 128.42 to 112.54 and 111.17, respectively, i.e., decreases by $13.24 \%$ and $13.43 \%$. Similarly, for new products (remanufactured products), their retail prices decrease by $5.83 \%(6.10 \%)$ and $11.47 \%(12.03 \%)$, respectively. Correspondingly, from Figure $4 c, d$, their demands in the direct sale channel increase by $16.31 \%(34.13 \%)$ and $2,019.57 \%(262.24 \%)$, respectively. As a result, in two cases, the total demands of new products in dual-sale channels increase from 225.88 and 225.92 to 244.37 and 244.50 , i.e., decreases by $8.19 \%$ and $8.22 \%$, respectively, while those of remanufactured products increase from 105.88 and 107.31 to 124.95 and 126.48 , i.e., decrease by $18.01 \%$ and $17.86 \%$, respectively. Correspondingly, from Figure 4f, the profits of the manufacturer and the retailer in the decentralized case increase by $8.32 \%$ and $2.68 \%$, and the system profits in two cases increase by $8.15 \%$ and $7.94 \%$. 
(2) When the carbon trading price increases, the manufacturer will raise the investment in carbon emission reduction and hence makes products more environment-friendly. From Figure 4e, when the carbon trading price rises from 0.1 to 0.17 in two cases, the carbon emission reductions per product increase from 165.88 and 166.62 to 313.93 and 315.33 , i.e., increase by $89.25 \%$ simultaneously. As a result, the manufacturer's carbon emission reduction investment increases by $72.08 \%$. Obviously, whether to reduce the cost of carbon emissions or to raise carbon trading revenue, the increase in carbon trading prices will prompt manufacturers to raise carbon emission reduction investments.
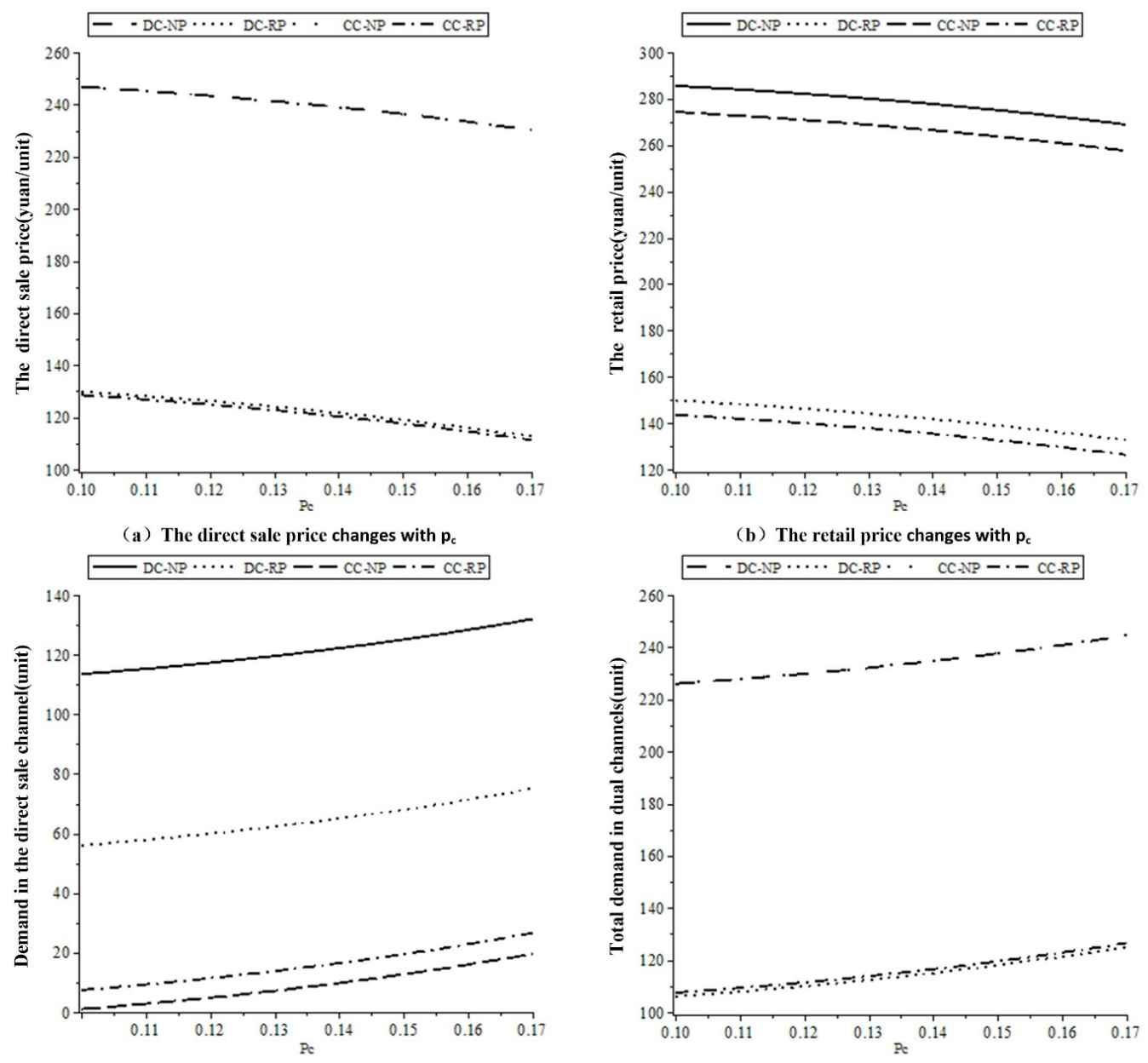

(c) Demand in the direet channel changes with $p_{c}$

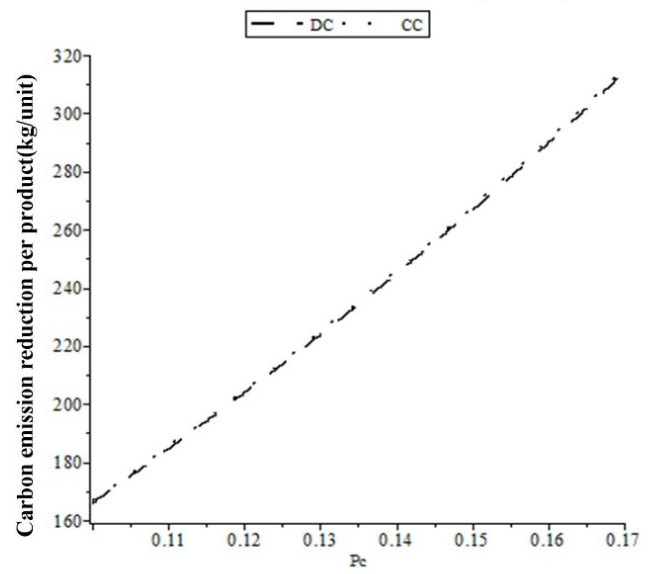

Total demand in dual channels changes with $p_{c}$

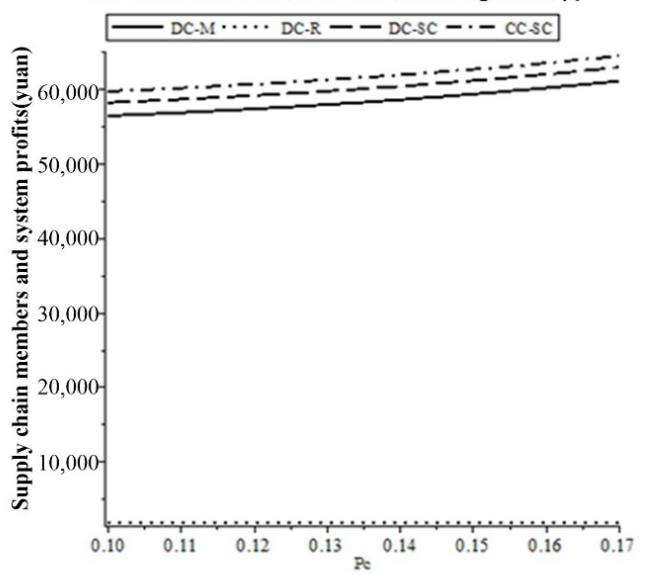

(f) Supply chain members and system profits change with $\mathrm{p}_{\mathrm{c}}$

(e) Carbon emission reduction per product changes with $\mathbf{p}_{c}$

Figure 4. The impact of $p_{c}$ on decision results in the decentralized and centralized cases. 


\section{Discussions, Policy Implications and Recommendations}

Compared with Model II of Yang et al. (2018) [30], our model is more complex and closer to reality. They assume that new products and remanufactured products are homogeneous and sell them at the same price in the same channels, and the direct sale price is equal to the retail price. As a result, they obtain the manufacturer's optimal pricing and emission reduction decisions $\left(w^{*}, p^{*}, \Delta e^{*}\right)$ and the retailer's optimal pricing decisions $p^{*}$, where there are three decision variables. In addition, they assume that the free carbon allowance is a constant, which cannot reflect the actual production situation of the enterprise and the pressure of the industry to reduce carbon emissions. In reality, since remanufactured products carry an obvious "remanufactured" logo, consumers can easily distinguish between new products and remanufactured products. Furthermore, due to the usage of raw material, the production cost of a new product is greater than that of a remanufactured one. Therefore, the price of remanufactured products is lower that of new products. For these reasons, we assume that new products and remanufactured products are heterogeneous and have different selling prices in the same channels and the same type of products compete in different sale channels. Besides these, we use the historical intensity method to allocate free carbon allowances and let the free carbon emission allowances $=$ the actual output $\times$ the historical intensity value $\times$ the industry emission control coefficient. Correspondingly, we obtain the manufacturer's optimal pricing and emission reduction decisions $\left(w_{n}^{*}, w_{r}^{*}, p_{m n}^{*}, p_{m r}^{*}, \Delta e^{*}\right)$ and the retailer's optimal pricing decisions $\left(p_{r n}^{*}, p_{r r}^{*}\right)$, where there are seven decision variables. Obviously, our model is more general and can better reflect the actual operation of enterprises.

Compared with Xu et al. (2018) [32], our decisions are more feasible to the practical operation of enterprises. Since we consider the selling costs per product of the retailer in the retail channel and the manufacturer in the direct sale channel, from Table 2 in Section 6.1, we know that in the decentralized case and coordinated case, the wholesale prices of new products and remanufactured products are lower than their direct sales prices, which makes the retail channel still exist even if there is an online direct sale channel. In other words, new products and remanufactured products are sold simultaneously in direct and retail channels. However, from Table 2 of $\mathrm{Xu}$ et al. (2018) [32], we find that in the decentralized case, the direct sale price is lower than the wholesale price, which allows the retailer to wholesale products via the direct sale channel instead of the retail channel. At this time, the manufacturer only sell products via the direct sale channel and traditional retail channels will disappear. In a word, we make up for the lack of research by Xu et al. (2018) [32].

So far, from Corollary 1-3, Theorem 3 and numerical analysis, we get the following policy implications and recommendations:

(1) Optimizing the carbon trading mechanism is conducive to carbon emission reduction and improving the profits of the supply chain system and members. The government should determine the right industry emission control coefficient to encourage manufacturers to increase investment in carbon emission reduction technologies and maintain carbon trading prices at a high level through relevant policy measures, such as adjusting auctioned carbon emission allowances or the carbon emission allowance auction ratio.

(2) The increase in the direct sale channel preference coefficient will help raise the profits of the sale entities and the supply chain system, and the manufacturers' investment in carbon emission reduction. Therefore, whether it is the manufacturer or the retailer, improving the customer's shopping experience, such as a faster order response speed, more efficient logistics services, better after-sales service and others, is very important for retaining old customers, attracting new customers, and reducing customer loss.

(3) Strengthening the collaboration between supply chain members is of great significance to increase their profits and reduce carbon emissions per product. Since the development of online direct sales channels by the manufacturer can cannibalize the retailer's sales and reduce retailer's profits, to win the support of the retailer, the manufacturer should take the initiative to design 
reasonable revenue-sharing contracts. In addition, to improve the environmental and economic benefits simultaneously, the manufacturer and the retailer should make joint decisions based on revenue-sharing contracts.

\section{Conclusions and Further Research}

Considering the investment for carbon emission reduction, a dual-sale channel remanufacturing supply chain is investigated under a CCT-mechanism. Firstly, two decision-making models in decentralized and centralized cases are developed with the historical intensity method. Secondly, the corresponding solution procedures on decision variables are given and the effect of the industry control emission coefficient is analyzed. Thirdly, two decision cases are compared and a coordination mechanism is designed based on a contract of revenue-sharing. Finally, a numerical analysis is given. Here are the important findings: (1) To reduce carbon emissions per product, the industry emission control coefficient and the free carbon emission allowances granted to the manufacturer should be raised as much as possible. (2) When consumers' preference for the direct sale channel increases, the profits for the manufacturer and the entire system will increase while the retailer profit will decrease. Obviously, to raise the profits for the manufacturer and the retailer, the improvement of channel service capabilities is important, for it can raise the channel's stickiness to customers. (3) Keeping carbon trading prices at a higher level requires the manufacturer to make more carbon emission reduction investment and brings more profits for the system and its members. (4) Compared with decentralized and centralized cases, the coordination case with the contract of revenue-sharing is better. This is because the system profit in the coordinated case equals that in the centralized case and the manufacturer and the retailers can make more profits than those in decentralized cases. Of course, since this article adopts the "grandfather" carbon allowance allocation method under the carbon trading mechanism, the above conclusions are valid when the carbon allowance allocation method is "grandfather".

It should be noted that: (1) The above management enlightenment is applicable in most cases under China's carbon trading mechanism. However, it is needed to determine whether the situation of carbon allowance auctions and other carbon allowance allocations methods are applicable. (2) Limited by the difficulty of collecting carbon emissions and carbon trading data from remanufacturing enterprises, we are currently unable to verify some assumptions underlying the model or buttress the inferences drawn from the modelling through empirical analysis. For example, as the industry emission control coefficient increases, the carbon emissions per unit product will decrease; when the carbon trading price is higher, the manufacturer's carbon emission reduction investment will increase. Whether these conclusions are valid in a specific industry requires further empirical research. Obviously, once the data related to carbon trading of remanufacturing enterprises are obtained it will be an interesting study to conduct an empirical analysis of some hypotheses and conclusions of this paper. (3) We assume that no competition exists between both types of products if sold in independent markets, respectively. In practice, it is possible for them to have a competitive substitution relationship. New products may be replaced by remanufactured products or vice versa. Therefore, under a CCT-mechanism, the pricing and emission reduction issues of the remanufacturing supply chain considering the competitive substitution relationship also need to be further studied.

Author Contributions: Conceptualization, review and funding acquisition, K.Y.; writing-manuscript revision and editing, G.W.; writing-original draft preparation, H.D.; review and comment, B.H.; methodology, D.W. All authors have read and agreed to the published version of the manuscript.

Funding: The research is supported by the National Natural Science Foundation of China (grant number 71661003, 71572021, 71761005), and Guizhou University of Finance and Economics Innovation Exploration and Academic New Seedling Project (grant number Qiankehe Pingtai Rencai (2017)5736-017).

Conflicts of Interest: The authors declare no conflict of interest. 


\section{Appendix A. The Proofs for Demand Functions}

It can be noticed from Assumption 4 that consumers' preference coefficients for both channels are 1 and $x$, respectively, $0<x<1$. The greater the $x$, the higher consumers' acceptance level of products purchased by the direct sale channel. Consumers' expected values for products are dictated by the uniform distribution of $\left[0, Q_{i}\right], i \in\{n, r\}$, where $n$ and $r$ refer to new product and remanufactured product, respectively.

For the new product market, the expected values of consumers purchasing new products through the retail channel and the direct sale channel are $v$ and $x v$, respectively. From the consumer purchasing utility theory, the utilities obtained by consumers to purchase new products in both channels are $v-p_{r n}$ and $x v-p_{m n}$, respectively. Only when $v-p_{r n} \geq 0$ can consumers purchase new products through the retail channel. Let $v^{r}=p_{r n}$, where $v^{r}$ is the marginal value of consumers purchasing new products through the retail channel. Only when $x v-p_{m n} \geq 0$ can consumers buy new products through the direct sale channel. Let $v^{m}=\frac{p_{m n}}{x}$, where $v^{m}$ is the marginal value of consumers buying new products through the direct sale channel.

When $v-p_{r n} \geq x v-p_{m n}$ and $v-p_{r n} \geq 0$, consumers purchase new products through the retail channel; when $x v-p_{m n} \geq v-p_{r n}$ and $x v-p_{m n} \geq 0$, consumers purchase new products through the direct sale channel. Let $v^{r m}=\frac{p_{r n}-p_{m n}}{1-x}$, where $v^{r m}$ is the marginal value of consumer channel selection by comparing the utility of two channels to purchase new products. When $v \geq v^{r m}$, consumers purchase new products in the retail channel—otherwise, in the direct sale channel.

When $v \geq v^{r}$ and $v \geq v^{r m}$, consumers purchase new products via the retail channel. There are two cases:

(1) When $v^{r m} \geq v^{r}$, i.e., $p_{m n} \leq x p_{r n}$ and $v \in\left[v^{r m}, Q_{n}\right]$, we have $D_{r n}=Q_{n} \int_{v^{r m}}^{Q_{n}} \frac{1}{Q_{n}} d v=Q_{n}-v^{r m}$, i.e., $D_{r n}=Q_{n}-\frac{p_{r n}-p_{m n}}{1-x}$.

(2) When $v^{r m}<v^{r}$, i.e., $p_{m n}>x p_{r n}$ and $v \in\left[v^{r}, Q_{n}\right]$, we have $D_{r n}=Q_{n} \int_{v^{r}}^{Q_{n}} \frac{1}{Q_{n}} d v=Q_{n}-v^{r}$, i.e., $D_{r n}=Q_{n}-p_{r n}$.

When $v \geq v^{m}$ and $v \leq v^{r m}$, consumers choose the direct sale channel to purchase new products, there are two cases:

(1) When $v^{r m} \geq v^{m}$, i.e., $p_{m n} \leq x p_{r n}$ and $v \in\left[v^{m}, v^{r m}\right]$, we have $D_{m n}=Q_{n} \int_{v^{m}}^{v^{r m}} \frac{1}{Q_{n}} d v=v^{r m}-v^{m}$, i.e., $D_{m n}=\frac{x p_{r n}-p_{m n}}{x(1-x)}$.

(2) When $v^{r m}<v^{m}$, i.e., $p_{m n}>x p_{m n}$, consumers do not choose the direct sale channel to purchase new products, we have $D_{m n}=0$.

Similarly, for the remanufactured product market,

When $p_{m r} \leq x p_{r r}$, we have $D_{r r}=Q_{r}-\frac{p_{r r}-p_{m r}}{1-x}, D_{m r}=\frac{x p_{r r}-p_{m r}}{x(1-x)}$.

When $p_{m r}>x p_{r r}$, we have $D_{r r}=Q_{r}-p_{r r}, D_{m r}=0$.

In summary, we have four cases on demand functions:

Case 1: When $p_{m n} \leq x p_{r n}$ and $p_{m r} \leq x p_{r r}$,

$$
D_{r n}=Q_{n}-\frac{p_{r n}-p_{m n}}{1-x}, D_{m n}=\frac{x p_{r n}-p_{m n}}{x(1-x)}, D_{r r}=Q_{r}-\frac{p_{r r}-p_{m r}}{1-x}, D_{m r}=\frac{x p_{r r}-p_{m r}}{x(1-x)} .
$$

In Case 1, both types of products are sold via both channels.

Case 2: When $p_{m n} \leq x p_{r n}$ and $p_{m r}>x p_{r r}$,

$$
D_{r n}=Q_{n}-\frac{p_{r n}-p_{m n}}{1-x}, D_{m n}=\frac{x p_{r n}-p_{m n}}{x(1-x)}, D_{r r}=Q_{r}-p_{r r}, D_{m r}=0
$$

In Case 2, new products are sold via both channels while remanufactured ones are sold only via the retail channel. 
Case 3: When $p_{m n}>x p_{r n}$ and $p_{m r} \leq x p_{r r}$

$$
D_{r n}=Q_{n}-p_{r n}, D_{m n}=0, D_{r r}=Q_{r}-\frac{p_{r r}-p_{m r}}{1-x}, D_{m r}=\frac{x p_{r r}-p_{m r}}{x(1-x)} .
$$

In Case 3, new products are sold only via the retail channel while remanufactured ones are sold via both channels.

Case 4: When $p_{m n}>x p_{r n}$ and $p_{m r}>x p_{r r}$,

$$
D_{r n}=Q_{n}-p_{r n}, D_{m n}=0, D_{r r}=Q_{r}-p_{r r}, D_{m r}=0 \text {. }
$$

In Case 4, both types of products are sold only via the retail channel. At this time, the direct sale channel disappears.

So far, the demand functions for different products for different selling channels have been proved.

\section{Appendix B. The Proof for Theorem 1}

Firstly, considering the second stage of the game and using the backward induction from Equation (13), we get the Hessian matrix of $\pi_{r}$ and its leading principal minors as follows: $H\left(\pi_{r}\right)=$ $\left[\begin{array}{cc}-\frac{2}{1-x} & 0 \\ 0 & -\frac{2}{1-x}\end{array}\right],\left|H_{1}\left(\pi_{r}\right)\right|=-\frac{2}{1-x}<0,\left|H_{2}\left(\pi_{r}\right)\right|=\frac{4}{(1-x)^{2}}>0$. Due to $\left|H_{1}\left(\pi_{r}\right)\right|<0$ and $\left|H_{2}\left(\pi_{r}\right)\right|>0$, $H\left(\pi_{r}\right)$ is negative definite and has a unique maximum value, where $\pi_{r}$ is a joint concave function w.r.t $p_{r n}, p_{r r}$. Letting the first partial derivatives for $\pi_{r}$ of $p_{r n}, p_{r r}$ be 0 , we get

$$
\begin{gathered}
\frac{\partial \pi_{r}}{\partial p_{r n}}=Q_{n}-\frac{2 p_{r n}-p_{m n}-w_{n}-c_{h}}{1-x}=0 \\
\frac{\partial \pi_{r}}{\partial p_{r r}}=Q_{r}-\frac{2 p_{r r}-p_{m r}-w_{r}-c_{h}}{1-x}=0
\end{gathered}
$$

From (A1) and (A2), we get the retailer's response functions as follows:

$$
\begin{aligned}
& p_{r n}=\frac{Q_{n}(1-x)+p_{m n}+w_{n}+c_{h}}{2} \\
& p_{r r}=\frac{Q_{r}(1-x)+p_{m r}+w_{r}+c_{h}}{2}
\end{aligned}
$$

Substituting (A3) and (A4) into (12), the Hessian matrix of $\pi_{m}$ and its leading principal minors are given as follows: $H\left(\pi_{m}\right)=\left[\begin{array}{ccccc}-\frac{1}{1-x} & \frac{1}{1-x} & 0 & 0 & 0 \\ \frac{1}{1-x} & \frac{x-2}{x(1-x)} & 0 & 0 & -\frac{p_{c}}{x} \\ 0 & 0 & -\frac{1}{1-x} & \frac{1}{1-x} & 0 \\ 0 & 0 & \frac{1}{1-x} & \frac{x-2}{x(1-x)} & -\frac{p_{c}}{x} \\ 0 & -\frac{p_{c}}{x} & 0 & -\frac{p_{c}}{x} & -2 \lambda\end{array}\right],\left|H_{1}\left(\pi_{m}\right)\right|=-\frac{1}{1-x}<0,\left|H_{2}\left(\pi_{m}\right)\right|=$ $\frac{2}{x(1-x)}>0,\left|H_{3}\left(\pi_{m}\right)\right|=\frac{-2}{x(1-x)^{2}}<0,\left|H_{4}\left(\pi_{m}\right)\right|=\frac{4}{x^{2}(1-x)^{3}}>0,\left|H_{5}\left(\pi_{m}\right)\right|=\frac{p_{c}^{2}(1-x)-2 \lambda(x-2)^{2}}{x^{2}(1-x)^{4}}$. Only when $p_{c}^{2}(1-x)-2 \lambda(x-2)^{2}<0$, we have $\left|H_{5}\left(\pi_{m}\right)\right|<0$. In other words, when $p_{c}^{2}(1-x)-2 \lambda(x-2)^{2}<0$, $H\left(\pi_{m}\right)$ is a negative definite and has a unique maximum value, where $\pi_{m}$ is a joint concave function w.r.t $w_{n}, w_{r}, \Delta e, p_{m n}, p_{m r}$. Letting the first partial derivatives for $\pi_{m}$ of $w_{n}, w_{r}, \Delta e, p_{m n}, p_{m r}$ be 0 , we have

$$
\begin{gathered}
\frac{\partial \pi_{m}}{\partial w_{n}}=\frac{1}{2} Q_{n}+\frac{2 p_{m n}-2 w_{n}-c_{d}-c_{h}}{2(1-x)}=0 \\
\frac{\partial \pi_{m}}{\partial w_{r}}=\frac{1}{2} Q_{r}+\frac{2 p_{m r}-2 w_{r}-c_{d}-c_{h}}{2(1-x)}=0
\end{gathered}
$$




$$
\begin{gathered}
\frac{\partial \pi_{m}}{\partial p_{m n}}=\frac{Q_{n} x^{2}+\left\{\left[2(1-a) e_{n}-2 \Delta e\right] p_{c}-2 p_{m n}-Q_{n}+c_{d}-c_{h}+2 c_{n}-2 w_{n}\right\} x}{2 x(x-1)} \\
+\frac{\left[2(a-1) e_{n}+2 \Delta e\right] p_{c}+4 p_{m n}-2 c_{d}-2 c_{n}}{2 x(x-1)}=0 \\
\frac{\partial \pi_{m}}{\partial p_{m r}}=\frac{Q_{r} x^{2}+\left\{\left[2(1-a) e_{r}-2 \Delta e\right] p_{c}+2(1+\sigma) p_{j}-2 p_{m n}-Q_{r}+c_{d}-c_{h}+2 c_{r}-2 w_{r}\right\} x}{2 x(x-1)} \\
+\frac{\left[2(a-1) e_{r}+2 \Delta e\right] p_{c}-2(1+\sigma) p_{j}+4 p_{m n}-2 c_{d}-2 c_{r}}{2 x(x-1)}=0 \\
\frac{\partial \pi_{m}}{\partial \Delta e}=\frac{\left[\left(Q_{n}+Q_{r}\right) x-p_{m n}-p_{m r}\right] p_{c}-2 \lambda x \Delta e}{x}=0
\end{gathered}
$$

From Equations (A5)-(A9), we get the manufacturer's optimal decisions of pricing and emission reduction $\left(w_{n}^{D C}, w_{r}^{D C}, p_{m n}^{D C}, p_{m r}^{D C}, \Delta e^{D C}\right)$. Then, by substituting $\left(w_{n}^{D C}, w_{r}^{D C}, p_{m n}^{D C}, p_{m r}^{D C}\right)$ into Equations (A3) and (A4), we get the retailer's optimal pricing decision $\left(p_{r n}^{D C}, p_{r r}^{D C}\right)$. Correspondingly, we also get the demands of both types of products $\left(D_{m n}^{D C}, D_{m r}^{D C}, D_{r n}^{D C}, D_{r r}^{D C}\right)$. So far, Theorem 1 has been proved.

\section{Appendix C. The Proof for Corollary 1}

According to Theorem 1 , the first partial derivatives of $w_{n}^{D C}, w_{r}^{D C}, p_{m n}^{D C}, p_{m r}^{D C}, p_{r n}^{D C}, p_{r r}^{D C}, \Delta e^{D C}$, $D_{n}^{D C}, D_{r}^{D C}$ of $a$ are as follows:

$$
\begin{gathered}
\frac{\partial w_{n}^{D C}}{\partial a}=\frac{e_{n} p_{c}\left(p_{c}^{2}-4 \lambda x\right)-e_{r} p_{c}^{3}}{4\left(2 \lambda x-p_{c}^{2}\right)} \\
\frac{\partial w_{r}^{D C}}{\partial a}=\frac{e_{r} p_{c}\left(p_{c}^{2}-4 \lambda x\right)-e_{n} p_{c}^{3}}{4\left(2 \lambda x-p_{c}^{2}\right)} \\
\frac{\partial p_{m n}^{D C}}{\partial a}=\frac{e_{n} p_{c}\left(p_{c}^{2}-4 \lambda x\right)-e_{r} p_{c}^{3}}{4\left(2 \lambda x-p_{c}^{2}\right)} \\
\frac{\partial p_{m r}^{D C}}{\partial a}=\frac{e_{r} p_{c}\left(p_{c}^{2}-4 \lambda x\right)-e_{n} p_{c}^{3}}{4\left(2 \lambda x-p_{c}^{2}\right)} \\
\frac{\partial p_{r n}^{D C}}{\partial a}=\frac{e_{n} p_{c}\left(p_{c}^{2}-4 \lambda x\right)-e_{r} p_{c}^{3}}{4\left(2 \lambda x-p_{c}^{2}\right)} \\
\frac{\partial p_{r r}^{D C}}{\partial a}=\frac{e_{r} p_{c}\left(p_{c}^{2}-4 \lambda x\right)-e_{n} p_{c}^{3}}{4\left(2 \lambda x-p_{c}^{2}\right)} \\
\frac{\partial \Delta e^{D C}}{\partial a}=\frac{p_{c}^{2}\left(e_{n}+e_{r}\right)}{2\left(2 \lambda x-p_{c}^{2}\right)} \\
\frac{\partial D_{n}^{D C}}{\partial a}=\frac{e_{n} p_{c}\left(4 \lambda x-p_{c}^{2}\right)+e_{r} p_{c}^{3}}{4 x\left(2 \lambda x-p_{c}^{2}\right)} \\
\frac{\partial x}{\partial a}
\end{gathered}
$$

Only when the manufacturer makes a profit does his production and sales make sense, i.e., the manufacturer's revenue from sales of products is greater than the sum of production costs, direct sale channel sale costs and carbon trading costs. Consequently, we have $p_{m n}-c_{n}-$ $c_{d}+p_{c}\left(a e_{n}-e_{n}+\Delta e\right)>0$ and $p_{m r}-c_{r}-c_{d}-(1+\sigma) p_{j}+p_{c}\left(a e_{r}-e_{r}+\Delta e\right)>0$, where $\Delta e \geq 0$. Obviously, when $\Delta e=0$, we also have $p_{m n}-c_{n}-c_{d}+p_{c} e_{n}(a-1)>0, p_{m r}-c_{r}-c_{d}-(1+\sigma) p_{j}+p_{c} e_{r}(a-1)>0$. Then, we have $p_{m n}>c_{n}-p_{c} e_{n}(a-1)+c_{d}=A+c_{d}, p_{m r}>c_{r}+(1+\sigma) p_{j}-p_{c} e_{r}(a-1)+c_{d}=F+c_{d}$, where $A=c_{n}-p_{c} e_{n}(a-1), F=c_{r}+(1+\sigma) p_{j}-p_{c} e_{r}(a-1)$.

Due to $D_{n}=Q_{n}-\frac{p_{m n}}{x}>0$ and $D_{r}=Q_{r}-\frac{p_{m r}}{x}>0$, i.e., $Q_{n} x>p_{m n}, Q_{r} x>p_{m r}$, we get $Q_{n} x+Q_{r} x>$ $p_{m r}+p_{m n}$. Due to $p_{m n}>A+c_{d}$ and $p_{m r}>F+c_{d}$, we have $Q_{n} x+Q_{r} x-A-F-2 c_{d}>0$. Due to 
$\Delta e^{D C}=\frac{p_{c}\left[x\left(Q_{n}+Q_{r}\right)-A-F-2 c_{d}\right]}{2\left(2 \lambda x-p_{c}^{2}\right)}, \Delta e^{D C}>0$ and $Q_{n} x+Q_{r} x-A-F-2 c_{d}>0$, we have $2 \lambda x-p_{c}^{2}>0$. Due to $\left(4 \lambda x-p_{c}^{2}\right)-\left(2 \lambda x-p_{c}^{2}\right)=2 \lambda x>0$, we have $4 \lambda x-p_{c}^{2}>0$.

Due to $2 \lambda x-p_{c}^{2}>0$ and $4 \lambda x-p_{c}^{2}>0$, we have $\frac{\partial w_{n}^{D C}}{\partial a}<0, \frac{\partial w_{r}^{D C}}{\partial a}<0, \frac{\partial p_{m n}^{D C}}{\partial a}<0, \frac{\partial p_{m r}^{D C}}{\partial a}<0, \frac{\partial p_{r n}^{D C}}{\partial a}<0$, $\frac{\partial p_{r r}^{D C}}{\partial a}<0, \frac{\partial \Delta D^{D C}}{\partial a}>0, \frac{\partial D_{n}^{D C}}{\partial a}>0, \frac{\partial D_{r}^{D C}}{\partial a}>0$. So far, Corollary 1 has been proved.

\section{Appendix D. The Proof for Theorem 2}

The Hessian matrix of $\pi_{T}$ and its leading principal minors are as follows: $H\left(\pi_{T}\right)=$ $\left[\begin{array}{ccccc}\frac{-2}{1-x} & \frac{2}{1-x} & 0 & 0 & 0 \\ \frac{2}{1-x} & \frac{-2}{x(1-x)} & 0 & 0 & \frac{-p_{c}}{x} \\ 0 & 0 & \frac{-2}{1-x} & \frac{2}{1-x} & 0 \\ 0 & 0 & \frac{2}{1-x} & \frac{-2}{x(1-x)} & \frac{-p_{c}}{x} \\ 0 & \frac{-p_{c}}{x} & 0 & \frac{-p_{c}}{x} & \frac{-2 \lambda}{x}\end{array}\right],\left|H_{1}\left(\pi_{T}\right)\right|=-\frac{2}{1-x}<0,\left|H_{2}\left(\pi_{T}\right)\right|=\frac{4}{x(1-x)}>0,\left|H_{3}\left(\pi_{T}\right)\right|=\frac{-8}{x(1-x)^{2}}<$ $0,\left|H_{4}\left(\pi_{T}\right)\right|=\frac{16(1+x)}{x^{2}(1-x)^{3}}>0$ and $\left|H_{5}\left(\pi_{T}\right)\right|=\frac{8 p_{c}^{2}(1-x)-32 \lambda}{x^{2}(1-x)^{4}}$. Obviously, only when $8 p_{c}^{2}(1-x)-32 \lambda<0$, i.e., $p_{c}^{2}(1-x)-4 \lambda<0$, we have $\left|H_{5}\left(\pi_{T}\right)\right|<0$ and $H\left(\pi_{T}\right)$ is a negative definite. Consequently, when $p_{c}^{2}(1-x)-4 \lambda<0, \pi_{T}$ is a joint concave function of $w_{n}, w_{r}, \Delta e, p_{m n}, p_{m r}$ and has a unique maximum value. Let the first partial derivatives for $\pi_{T}$ of $p_{m n}, p_{m r}, p_{r n}, p_{r r}, \Delta e$ be zero, we have

$$
\begin{gathered}
\frac{\partial \pi_{T}}{\partial p_{r n}}=Q_{n}-\frac{2 p_{r n}-2 p_{m n}+c_{d}-c_{h}}{1-x}=0 \\
\frac{\partial \pi_{T}}{\partial p_{r r}}=Q_{r}-\frac{2 p_{r r}-2 p_{m r}+c_{d}-c_{h}}{1-x}=0 \\
\frac{\partial \pi_{T}}{\partial p_{m n}}=\frac{\left\{\left[(1-a) e_{n}-\Delta e\right] p_{c}+c_{h}+c_{n}-2 p_{r n}\right\} x+\left[(a-1) e_{n}+\Delta e\right] p_{c}+2 p_{m n}-c_{d}-c_{n}}{x(x-1)}=0 \\
\frac{\partial \pi_{T}}{\partial p_{m r}}=\frac{\left\{\left[(1-a) e_{r}-\Delta e\right] p_{c}+c_{h}+c_{r}+p_{j}-2 p_{r r}\right\} x+\left[(a-1) e_{r}+\Delta e\right] p_{c}}{x(x-1)} \\
+\frac{2 p_{m r}-c_{d}-c_{r}-p_{j}}{x(x-1)}=0 \\
\frac{\partial \pi_{T}}{\partial \Delta e}=\frac{\left[\left(Q_{n}+Q_{r}\right) x-p_{m n}-p_{m r}\right] p_{c}-2 \lambda x \Delta e}{x}=0
\end{gathered}
$$

From Equations (A19)-(A23), we get the optimal system decision $\left(p_{m n}^{C C}, p_{m r}^{C C}, p_{r n}^{C C}, p_{r r}^{C C}, \Delta e^{C C}\right)$. Correspondingly, we also get the demands of both types of products $\left(D_{m n}^{C C}, D_{m r}^{C C}, D_{r n}^{C C}, D_{r r}^{C C}\right)$. So far, Theorem 2 has been proved.

\section{Appendix E. The Proof for Corollary 2}

From Theorem 2, the first partial derivatives of $p_{m n}^{C C}, p_{m r}^{C C}, \Delta e^{C C}, p_{r n}^{C C}, p_{r r}^{C C}, D_{n}^{C C}, D_{r}^{C C}$ of $a$ are as follows:

$$
\begin{aligned}
\frac{\partial p_{m n}^{C C}}{\partial a} & =\frac{e_{n} p_{c}\left(p_{c}^{2}-4 \lambda x\right)-e_{r} p_{c}^{3}}{4\left(2 \lambda x-p_{c}^{2}\right)} \\
\frac{\partial p_{m r}^{C C}}{\partial a} & =\frac{e_{r} p_{c}\left(p_{c}^{2}-4 \lambda x\right)-e_{n} p_{c}^{3}}{4\left(2 \lambda x-p_{c}^{2}\right)} \\
\frac{\partial p_{r n}^{C C}}{\partial a} & =\frac{e_{n} p_{c}\left(p_{c}^{2}-4 \lambda x\right)-e_{r} p_{c}^{3}}{4\left(2 \lambda x-p_{c}^{2}\right)} \\
\frac{\partial p_{r r}^{C C}}{\partial a} & =\frac{e_{r} p_{c}\left(p_{c}^{2}-4 \lambda x\right)-e_{n} p_{c}^{3}}{4\left(2 \lambda x-p_{c}^{2}\right)}
\end{aligned}
$$




$$
\begin{gathered}
\frac{\partial \Delta e^{C C}}{\partial a}=\frac{p_{c}^{2}\left(e_{n}+e_{r}\right)}{2\left(2 \lambda x-p_{c}^{2}\right)} \\
\frac{\partial D_{n}^{C C}}{\partial a}=\frac{e_{n} p_{c}\left(4 \lambda x-p_{c}^{2}\right)+e_{r} p_{c}^{3}}{4 x\left(2 \lambda x-p_{c}^{2}\right)} \\
\frac{\partial D_{r}^{C C}}{\partial a}=\frac{e_{r} p_{c}\left(4 \lambda x-p_{c}^{2}\right)+e_{n} p_{c}^{3}}{4 x\left(2 \lambda x-p_{c}^{2}\right)}
\end{gathered}
$$

From Appendix $C$, we have $2 \lambda x-p_{c}^{2}>0$ and $4 \lambda x-p_{c}^{2}>0$, and substituting them into Equations (A24)-(A30), we have $\frac{\partial p_{m n}^{C C}}{\partial a}<0, \frac{\partial p_{m r}^{C C}}{\partial a}<0, \frac{\partial p_{r n}^{C C}}{\partial a}<0, \frac{\partial p_{r r}^{C C}}{\partial a}<0, \frac{\partial \Delta e^{C C}}{\partial a}>0, \frac{\partial D_{n}^{C C}}{\partial a}>0$, $\frac{\partial D_{r}^{C C}}{\partial a}>0$. So far, Corollary 2 has been proved.

\section{Appendix F. The Proof for Corollary 3}

From Theorem 1 and Theorem 2, we have

$$
\begin{aligned}
& p_{m n}^{D C}-p_{m n}^{C C}=\frac{\sigma p_{j} p_{c}^{2}}{4\left(2 \lambda x-p_{c}^{2}\right)} \\
& p_{m r}^{D C}-p_{m r}^{C C}=\frac{\sigma p_{j}\left(4 \lambda x-p_{c}^{2}\right)}{4\left(2 \lambda x-p_{c}^{2}\right)} \\
& p_{r n}^{D C}-p_{r n}^{C C}=\frac{\left(2 \lambda x-p_{c}^{2}\right)\left[(1-x) Q_{n}+c_{d}-c_{h}\right]+\sigma p_{j} p_{c}^{2}}{4\left(2 \lambda x-p_{c}^{2}\right)} \\
& p_{r r}^{D C}-p_{r r}^{C C}=\frac{\left(2 \lambda x-p_{c}^{2}\right)\left[(1-x) Q_{r}+c_{d}-c_{h}\right]+\left(4 \lambda x-p_{c}^{2}\right) \sigma p_{j}}{4\left(2 \lambda x-p_{c}^{2}\right)} \\
& \Delta e^{D C}-\Delta e^{C C}=\frac{-\sigma p_{j} p_{c}}{2\left(2 \lambda x-p_{c}^{2}\right)} \\
& D_{n}^{D C}-D_{n}^{C C}=\frac{-\sigma p_{j} p_{c}^{2}}{4 x\left(2 \lambda x-p_{c}^{2}\right)} \\
& D_{r}^{D C}-D_{r}^{C C}=\frac{-\left(4 \lambda x-p_{c}^{2}\right) \sigma p_{j}}{4 x\left(2 \lambda x-p_{c}^{2}\right)} \\
& \pi_{m}^{D C}+\pi_{r}^{D C}-\pi_{T}^{C C}=\frac{1}{16\left(2 \lambda x-p_{c}^{2}\right) x(1-x)}\left\{( p _ { c } ^ { 2 } - 2 \lambda x ) \left\{\left(Q_{n}^{2}+Q_{r}^{2}\right) x^{3}+2 x(1-x)\right.\right. \\
& \left.\left[Q_{n}\left(Q_{n}+c_{d}-c_{h}\right)+Q_{r}\left(Q_{r}+c_{d}-c_{h}\right)\right]+2 x\left(c_{d}-c_{h}\right)^{2}\right\} \\
& \left.+2 \sigma^{2} p_{j}^{2}(1-x)\left(p_{c}^{2}-4 \lambda x\right)\right\}
\end{aligned}
$$

From Appendix $C$, we have $2 \lambda x-p_{c}^{2}>0$ and $4 \lambda x-p_{c}^{2}>0$. Due to $c_{h}-c_{d} \leq(1-x) Q_{i}$, we have $(1-x) Q_{i}+c_{d}-c_{h} \geq 0$. Substituting it into Equations (A31)-(A38), we get $\Delta e^{D C}<\Delta e^{C C}, p_{m n}^{D C}>p_{m n}^{C C}$, $p_{m r}^{D C}>p_{m r}^{C C}, p_{r n}^{D C}>p_{r n}^{C C}, p_{r r}^{D C}>p_{r r}^{C C}, D_{n}^{D C}<D_{n}^{C C}, D_{r}^{D C}<D_{r}^{C C}, \pi_{m}^{D C}+\pi_{r}^{D C}<\pi_{T}^{C C}$. So far, Corollary 3 has been proved.

\section{Appendix G. The Proof for Theorem 3}

To raise the profits of supply chain members, we let the equilibrium decisions in accordance with the coordination mechanism to be the optimal decisions in the centralized case, i.e., $p_{m n}^{S}=p_{m n}^{C C}, p_{m r}^{S}=p_{m r}^{C C}, p_{r n}^{S}=p_{r n}^{C C}, p_{r r}^{S}=p_{r r}^{C C}, \Delta e^{S}=\Delta e^{C C}$. Solving these equations together, we get the relationships between the parameters of 
the revenue-sharing contract as follows: $\begin{gathered}w_{n}^{S}=\frac{\left\{-4 \lambda x\left(x Q_{n}+A-c_{d}+2 c_{h}\right)+p_{c}^{2}\left[\left(3 Q_{n}+Q_{r}\right) x+A-E-4 c_{d}+4 c_{h}\right]\right\} \psi}{4\left(2 \lambda x-p_{c}^{2}\right)} \\ +\frac{4 \lambda x\left(x Q_{n}+A-c_{d}\right)-p_{c}^{2}\left[\left(3 Q_{n}+Q_{r}\right) x+A-E-4 c_{d}\right]}{4\left(2 \lambda x-p_{c}^{2}\right)}\end{gathered}$, $w_{r}^{S}=\frac{\left\{-4 \lambda x\left(x Q_{r}+E-c_{d}+2 c_{h}\right)+p_{c}^{2}\left[\left(Q_{n}+3 Q_{r}\right) x-A+E-4 c_{d}+4 c_{h}\right]\right\} \psi}{4\left(2 \lambda x-p_{c}^{2}\right)}$
$+\frac{4 \lambda x\left(x Q_{r}+E-c_{d}\right)-p_{c}^{2}\left[\left(Q_{n}+3 Q_{r}\right) x-A+E-4 c_{d}\right]}{4\left(2 \lambda x-p_{c}^{2}\right)}$

, where the system profits in the coordinated and centralized cases are same. In addition, to ensure the effectiveness of the coordination mechanism and let supply chain members accept the revenue-sharing contract, we must ensure that the members' profits in the coordinated case are more than or equal to those in the decentralized case, i.e., $\pi_{m}^{S} \geq \pi_{m}^{D C}$, $\pi_{r}^{S} \geq \pi_{r}^{D C}$. Solving these two inequalities together, we get

$$
\begin{aligned}
& \frac{\sigma p_{j}\left(D_{m r}^{C C}+D_{r r}^{C C}\right)-c_{h}\left(D_{r n}^{C C}+D_{r r}^{C C}\right)+\left(p_{r n}^{C C}-w_{n}^{S}\right) D_{r n}^{C C}+\left(p_{r r}^{C C}-w_{r}^{S}\right) D_{r r}^{C C}-\pi_{r}^{D C}}{D_{r n}^{C C} p_{r n}^{C C}+D_{r r}^{C C} p_{r C}^{C C}} \geq \psi \\
& \geq \frac{A\left(D_{m n}^{C C}+D_{r n}^{C C}\right)+F\left(D_{m r}^{C C}+D_{r r}^{C C}\right)-\Delta e p_{c}\left(D_{m n}^{C C}+D_{m r}^{C C}+D_{r n}^{C C}+D_{r r}^{C C}\right)+c_{d}\left(D_{m n}^{C C}+D_{m r}^{C C}\right)}{D_{r n}^{C C} p_{r n}^{C C}+D_{r r}^{C C} p_{r r}^{C C}} \\
& +\frac{-D_{m n}^{C C} p_{m n}^{C C}-D_{m r}^{C C} p_{m r}^{C C}-D_{r n}^{C C} w_{n}^{C}-D_{r r}^{C C} w_{r}^{S}+\lambda\left(e^{C C}\right)^{2}+\pi_{m}^{C C}}{D_{r n}^{C C} p_{r n}^{C C}+D_{r r}^{C C} p_{r r}^{C C}}
\end{aligned}
$$

So far, Theorem 3 has been proved.

\section{References}

1. NBSC. China Statistical Yearbook 2007; China Statistics Press: Beijing, China, 2008.

2. NBSC. China Statistical Yearbook 2017; China Statistics Press: Beijing, China, 2018.

3. The State Council of the PRC. Regulations on the Management of Waste Electrical and Electronic Products' Recycling; The State Council of the PRC: Beijing, China, 2009.

4. Majumder, P.; Groenevelt, H. Competition in remanufacturing. Prod. Oper. Manag. 2001, 10, 125-141. [CrossRef]

5. Johnson, M.R.; McCarthy, I.P. Product recovery decisions within the context of extended producer responsibility. J. Eng. Technol. Manag. 2014, 34, 9-28. [CrossRef]

6. Cao, J.; Chen, X.H.; Zhang, X.P.; Gao, Y.C.; Zhang, X.M.; Zhao, Y.W.; Yang, X.L.; Xu, J.Y.; Zhou, G.G.; Schnoor, J.L. Public awareness of remanufactured products in Yangtze River Delta of China: Present status, problems and recommendations. Int. J. Environ. Res. Public Health 2018, 15, 1199. [CrossRef]

7. Singhal, D.; Tripathy, S.; Jena, S.K. Remanufacturing for the circular economy: Study and evaluation of critical factors. Resour. Conserv. Recycl. 2020, 156, 104681-104693. [CrossRef]

8. Martin, P.; Guide, V.D.R., Jr.; Craighead, C.W. Supply chain sourcing in remanufacturing operations: An empirical investigation of remake versus buy. Decis. Sci. 2010, 41, 301-324. [CrossRef]

9. Subramoniam, R.; Huisingh, D.; Chinnam, R.B.; Subramoniam, S. Remanufacturing Decision-Making Framework (RDMF): Research validation using the analytical hierarchical process. J. Clean. Prod. 2013, 40, 212-220. [CrossRef]

10. Ding, Q.; Dong, C.; Pan, Z. A hierarchical pricing decision process on a dual channel problem with one manufacturer and one retailer. Int. J. Prod. Econ. 2016, 175, 197-212. [CrossRef]

11. Kumar, S.; Craig, S. Dell, Inc.'s closed loop supply chain for computer assembly plants. Inf. Knowl. Syst. Manag. 2007, 6, 197-214.

12. Souza, G.C. Remanufacturing in closed-loop supply chains. Prod. Inventory Manag. J. 2009, 45, 56-66.

13. Chang, X.Y.; Xia, H.Y.; Zhu, H.Y.; Fan, T.J.; Zhao, H.Q. Production decisions in a hybrid manufacturingremanufacturing system with carbon cap and trade mechanism. Int. J. Prod. Econ. 2015, 162, 160-173. [CrossRef]

14. Yenipazarli, A. Managing new and remanufactured products to mitigate environmental damage under emissions regulation. Eur. J. Oper. Res. 2016, 249, 117-130. [CrossRef]

15. Chang, X.Y.; Li, Y.P.; Zhao, Y.B.; Liu, W.J.; Wu, J. Effects of carbon permits allocation methods on remanufacturing production decisions. J. Clean. Prod. 2017, 152, 281-294. [CrossRef]

16. García-Alvarado, M.; Paquet, M.; Chaabane, A.; Amodeo, L. Inventory management under joint product recovery and cap-and trade constraints. J. Clean. Prod. 2017, 167, 1499-1517. [CrossRef] 
17. Wang, Y.; Chen, W.; Li, B. Manufacturing/remanufacturing decisions for a capital-constrained manufacturer considering carbon emission cap and trade. J. Clean. Prod. 2017, 140, 1118-1128. [CrossRef]

18. Chai, Q.F.; Xiao, Z.D.; Lai, K.H.; Zhou, G.H. Can carbon cap and trade mechanism be beneficial for remanufacturing? Int. J. Prod. Econ. 2018, 203, 311-321. [CrossRef]

19. Chen, Y.; Li, B.; Bai, Q.; Liu, Z. Decision-making and environmental implications under cap-and-trade and take-back regulations. Int. J. Environ. Res. Public Health 2018, 15, 678. [CrossRef] [PubMed]

20. Turki, S.; Sauvey, C.; Rezg, N. Modelling and optimization of a manufacturing/remanufacturing system with storage facility under carbon cap and trade policy. J. Clean. Prod. 2018, 193, 441-458. [CrossRef]

21. Kundu, S.; Chakrabarti, T. Impact of carbon emission policies on manufacturing, remanufacturing and collection of used item decisions with price dependent return rate. Opsearch 2018, 55, 532-555. [CrossRef]

22. Wang, X.F.; Zhu, Y.T.; Sun, H.; Jia, F. Production decisions of new and remanufactured products: Implications for low carbon emission economy. J. Clean. Prod. 2018, 171, 1225-1243. [CrossRef]

23. Shu, T.; Huang, C.F.; Chen, S.; Wang, S.Y.; Lai, K.K. Trade-old-for-remanufactured closed-Loop supply chains with carbon tax and government subsidies. Sustainability 2018, 10, 3935. [CrossRef]

24. Miao, Z.W.; Mao, H.Q.; Fu, K.; Wang, Y. Remanufacturing with trade-ins under carbon regulations. Comput. Oper. Res. 2018, 89, 253-268. [CrossRef]

25. Dou, G.; Guo, H.; Zhang, Q. A two-period carbon tax regulation for manufacturing and remanufacturing production planning. Comput. Ind. Eng. 2019, 128, 502-513. [CrossRef]

26. Gao, J.; Wang, X.; Yang, Q.L.; Zhong, Q. Pricing decisions of a dual-channel closed-loop supply chain under uncertain demand of indirect channel. Math. Probl. Eng. 2016, 2016, 6053510. [CrossRef]

27. Wang, Z.B.; Wang, Y.Y.; Wang, J.C. Optimal distribution channel strategy for new and remanufactured products. Electron. Commer. Res. 2016, 16, 269-295. [CrossRef]

28. Gan, S.S.; Pujawan, I.N.; Suparno; Widodo, B. Pricing decision model for new and remanufactured short-life cycle products with time-dependent demand. Oper. Res. Perspect. 2015, 2, 1-12. [CrossRef]

29. Gan, S.S.; Pujawan, I.N.; Suparno; Widodo, B. Pricing decision for new and remanufactured product in a closed-loop supply chain with separate sales-channel. Int. J. Prod. Econ. 2017, 190, 120-132. [CrossRef]

30. Yang, L.; Wang, G.; Ke, C. Remanufacturing and promotion in dual-channel supply chains under cap-and-trade regulation. J. Clean. Prod. 2018, 204, 939-957. [CrossRef]

31. He, P.; He, Y.; Xu, H. Channel structure and pricing in a dual-channel closed-loop supply chain with government subsidy. Int. J. Prod. Econ. 2019, 213, 108-123. [CrossRef]

32. Xu, L.; Wang, C.X.; Zhao, J.J. Decision and coordination in the dual-channel supply chain considering cap-and-trade regulation. J. Clean. Prod. 2018, 197, 551-561. [CrossRef]

33. HPDRC. Hubei Province's 2017 Carbon Emission Allowance Allocation Plan; Hubei Provincial Development and Reform Commission: Wuhan, China, 2018.

34. SDRC. Shanghai's 2017 Carbon Emission Allowance Allocation Plan; Shanghai Development and Reform Commission: Shanghai, China, 2017.

35. Liu, Z.G.; Anderson, T.D.; Cruz, J.M. Consumer environmental awareness and competition in two-stage supply chains. Eur. J. Oper. Res. 2018, 218, 602-613. [CrossRef]

(C) 2020 by the authors. Licensee MDPI, Basel, Switzerland. This article is an open access article distributed under the terms and conditions of the Creative Commons Attribution (CC BY) license (http://creativecommons.org/licenses/by/4.0/). 